\title{
Rift-drift transition in the Red Sea: a rheological model of the early stage of seafloor spreading
}

\author{
Antonio Schettino, ${ }^{1}$ Giorgio Ranalli, ${ }^{2}$ Elisa Fierro, ${ }^{1}$ Pietro Paolo Pierantoni, ${ }^{1}$ \\ Davide Zanoni ${ }^{\oplus},{ }^{3}$ Eugenio Turco ${ }^{1}$ and Najeeb Rasul ${ }^{4}$ \\ ${ }^{1}$ School of Science and Technology - Geology Division, University of Camerino, Via Gentile III da Varano, I-62032 Camerino (MC), Italy. \\ E-mail: antonio.schettino@unicam.it \\ ${ }^{2}$ Department of Earth Sciences, Carleton University, Ottawa, ON K1S 5B6, Canada \\ ${ }^{3}$ Università degli Studi di Milano, Dipartimento di Scienze della 'Terra A. Desio', Via Mangiagalli 34, I-20133 Milano, Italy \\ ${ }^{4}$ Saudi Geological Survey, 21514 Jeddah, Saudi Arabia
}

\section{SUMMAR Y}

We present a rheological model of the continental lithosphere during the rift-drift transition, founded on theoretical considerations, numerical modelling, and supported by geophysical and geological evidence from the Red Sea region. The model is based on the fundamental assumption that during the rifting phase the necking lithospheric mantle of the conjugate continental margins retains and accumulates elastic strain. This hypothesis is tested numerically, and thereby it is shown that during the phase of extension the uppermost mantle has the capability to store and maintain recoverable elastic strain over geological times, differently from the upper crust, which exhibits a continuous short-term irreversible deformation by seismic release. After the onset of seafloor spreading, strain recovery and release of the strain energy accumulated in the lithospheric mantle occurs through a phase of non-linear anelastic relaxation. During this phase, the upper crust of the conjugate continental margins experiences post-rift deformation with tectonic inversion of former extensional structures, while the extra space created along the axial zone as a consequence of the rapid contraction of the margins triggers a rapid upwelling of the asthenosphere that induces an initial pulse of fast spreading followed by a steady phase of oceanic crust accretion. We present geophysical evidence supporting this model, including: (1) the observed pattern of oceanic magnetic anomalies in the Red Sea, (2) the distribution of finite crustal strains across the continental margins of Nubia and Arabia, and (3) the distribution of earthquake epicentres along the western margin of the Arabian Plate. We also present new structural data acquired during three geological campaigns performed in 2015 and 2016 along the western Arabian margin, which are consistent with a post-rift phase of compression and inversion of the rift structures. We will also show that a selection of realistic rheological parameters supports non-linear viscoelastic behaviour of the continental lithosphere during the rift-drift transition. Finally, we will show that in the case of the Red Sea $\sim 40$ per cent of the total extensional strain accumulated during the rifting stage has been recovered in the southernmost part of the Arabian margin conjugate to the Nubian Plate $\left(\sim 19^{\circ} \mathrm{N}\right)$, while this percentage decreases to $\sim 14$ per cent around $23.8^{\circ} \mathrm{N}$, where the continental margin faces the youngest spreading segment, and it is zero north of this area, where the Red Sea is still in the rifting stage. Taking into account of the age of oceanization along the central and northern Red Sea, this implies an average recovery of $\sim 10$ per cent $\mathrm{Myr}^{-1}$.

Key words: Continental margins: divergent; Dynamics of lithosphere and mantle; Rheology: mantle; Elasticity and anelasticity; Numerical modelling; Kinematics of crustal and mantle deformation. 


\section{INTRODUCTION}

Geological and geophysical evidence shows that the birth of a new ocean from a rift basin proceeds by steps, with the development of new linear spreading segments by growth and coalescence of small oceanic cells that form within the areas of maximum extension (Bonatti 1985), rather than being represented by a continuous, progressive break-up along the rift axis. Geological studies of the eastern North America rift basins facing the central Atlantic also suggest that the formation of new spreading segments is accompanied by episodes of post-rift contraction and inversion of the rift structures along the continental margins (Withjack et al. 1995; Schlische et al. 2003). A widely accepted explanation for post-rift contraction is that in the case of volcanic passive margins, but possibly also along magma-poor margins, an initial active pulse of fast spreading accompanies the onset of oceanic accretion before a steady equilibrium state establishes between far-field plate velocities and rate of MORB accretion. Consequently, all these models ascribe the initial fast pulse of seafloor spreading to small-scale mantle convection (e.g. Lucazeau et al. 2008; Ligi et al. 2011, 2012; Korostelev et al. 2015, 2016; cf. Section 7).

The sketch map in Fig. 1 illustrates an alternative scenario for the transformation of a rift axial zone into a mid-ocean ridge, based on the anelastic relaxation hypothesis proposed by Schettino et al. (2016). In this model, a new spreading segment forms by axial propagation of a localized rupture, while the continental margins shorten by release of elastic strain accumulated during the rifting phase. Consequently, for a small time interval at the riftdrift transition a wider continental gap forms along the axial zone than what is required by the far-field relative velocity between the two plates, determining passively an increased upwelling of the asthenosphere accompanied by fast seafloor spreading. The tenability of this hypothesis, which has been recently formulated by Schettino et al. (2016) for the Red Sea region, depends on specific rheological properties of the continental lithosphere: (1) the capability to retain and accumulate elastic energy during the rifting stage, which is not released by slip along extensional shear zones; (2) the capability to release this strain energy by longterm transient anelastic recovery during the rift-drift transition phase.

In this paper, we present geological and geophysical evidence from the Red Sea region (Fig. 2) showing that the early phases after the rift-drift transition are effectively characterized by diffuse contractional deformation along the newly formed continental margins. Consequently, the tectonic inversion of rift structures observed along the eastern North American margin would not represent a specific feature of that area but is the expression of a general process occurring just after the continental break-up. We also investigate the possibility that the transient mechanical behaviour of the thinned lithosphere during the phase of rifting, before the complete oceanization, and during the initial stage of drifting, just after the break-up, can be described by a Kelvin-Voigt rheology (e.g. Ranalli 1995), possibly associated with non-linear viscosity. This rheology implies delayed elasticity, characterized by time-dependent recovery and a decreasing strain rate under constant stress. An analogue model of Kelvin-Voigt materials is a two-element system consisting of a linear spring element and a dashpot connected in parallel. Although this rheology displays neither permanent strain after unloading nor instantaneous elastic response, it is appropriate for focusing on the anelasticity of the lithosphere in a continental rift over a transient time lapse of a few million years. A more realistic rheological behaviour that includes instantaneous elasticity and long-term steady creep is represented by the Burgers model (Fig. 3). In this study, we will ignore the instantaneous elasticity, which is released seismically in the upper crust and by localized shear below the brittle-ductile transition. Furthermore, we will consider the long-term steady creep, which is representative of stable tectonic conditions, only in the numerical simulations of the rifting phase. A transient viscosity associated with Kelvin-Voigt or Burgers rheology was first hypothesized by Peltier et al. (1980) and Peltier (1985) to explain the different mantle viscosities implied by postglacial rebound with respect to the isostatic geoid anomalies. Here we will show that the anelastic recovery has a time range of the order of $10^{4} \mathrm{yr}$ in the case of linear viscosity and $10^{6} \mathrm{yr}$ when the viscous rheology is non-linear. Specifically, assuming that (1) the elastic modulus of the linear Kelvin-Voigt element, $Y_{K}$, coincides with the anelastic modulus of olivine $\left(G_{R}=28-33 \mathrm{GPa}\right.$; Karato \& Wu 1993; Faul \& Jackson 2005) and (2) the transient viscosity $\eta_{K}$ is one order of magnitude lower than the steady-state viscosity, as suggested by observation of post-seismic deformation (e.g. Panet et al. 2010; Hoechner et al. 2011), the linear model predicts a very short relaxation time, of the order of a few thousand of years. This result is clearly incompatible with the geological and magnetic observations, which show a process that develops over a few million years. Conversely, assuming a non-linear behaviour, the strain rate decays to a background value between $10^{-16}$ and $10^{-18} \mathrm{~s}^{-1}$, typical of stable tectonic plate interiors (e.g. Liu \& Zoback 1997; see Section 5 ), in $\sim 1-2 \mathrm{Myr}$, which is compatible with the geological and geophysical observations from the central and southern Red Sea that will be presented in Sections 3 and 4 .

\section{GEOLOGICAL SETTING}

The Red Sea rift started about $30 \mathrm{Ma}$ within the Arabian-Nubian Shield, a Precambrian basement of Arabia and northeast Africa that was exhumed as a result of the rifting process. This basement is formed by Neoproterozoic rocks ranging in age from 1000 to $542 \mathrm{Ma}$ and includes metamorphic and igneous rocks produced during the Pan-African orogeny, as well as intra-oceanic arc terranes separated by ophiolite sutures (e.g. Hargrove et al. 2006; Fritz et al. 2013). Cenozoic sedimentary and volcanic rocks locally cover the Neoproterozoic basement. The rifting process, which started in the southern region close to Afar (e.g. Courtillot et al. 1987) and propagated northwards, was accompanied by widespread Cenozoic magmatism responsible for the volcanic fields (harrats) that occur all along the Arabian margin (Fig. 2). Magmatism is still active and associated with extensional deformation and seismicity in the Lunayyir zone (Pallister et al. 2010; Koulakov et al. 2014). It is well known that most of the faults activated during the Red Sea rifting are inherited N- to NE-trending Pan-African tectonic structures (Garson \& Krs 1976; Dixon et al. 1987; Makris \& Rihm 1991; Ghebreab \& Talbot 2000; Bosworth et al. 2005). One example of these structures is the Ad-Damm fault zone (AFZ) that separates the Jeddah and Asir terranes of the Arabian Shield and that recorded a Neoproterozoic polyphasic history in which convergent deformation was postdated by a dextral strike-slip kinematics (Hamimi et al. 2014); indeed, the AFZ was reactivated during the Red Sea opening (Schettino et al. 2016). Some of these inherited tectonic lines are still active as it is proven by the distribution of the present-day seismicity (Al-Saud 2008; Fnais et al. 2015). 

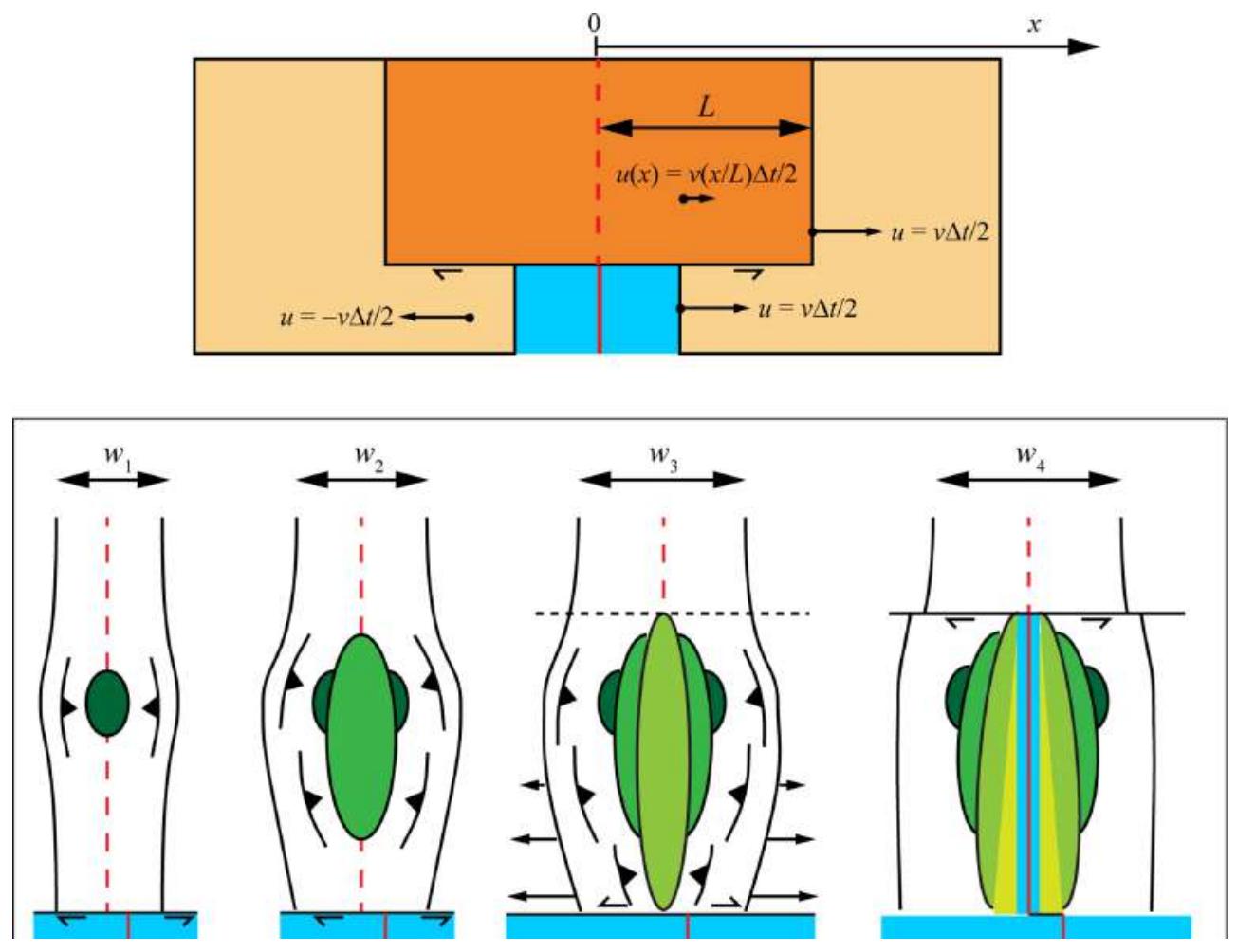

Figure 1. A model of formation of new spreading ridge segments. Top: origin of the strike-slip deformation at the boundary between oceanic area and active rifting zone. The stable passive margins and the undeformed region outside the rift are shown in ocra, while the region affected by extension is represented by the orange rectangle. For simplicity, a very far location of the Euler pole of relative motion is assumed so that the relative velocity between the two plates does not change significantly in the $\mathrm{N}-\mathrm{S}$ direction. Vectors indicate the amount of displacement, $u$, after a time interval $\Delta t$. $v$ is the full spreading or rifting rate. $L$ is the width of the rift zone. The model assumes homogeneous stretching of the continental lithosphere in the rift zone. The variation of velocity across the eastern strike-slip zone (south minus north) is $\delta v(x)=v(1-x / L) / 2$. Bottom, from left to right: It is assumed that the southern region is oceanic (in pale blue) and that steady MORB accretion proceeds along a stable spreading centre (red solid line). The northern area is still in a state of active rifting. A small oceanic deep (dark green oval) has formed along the rift axial zone (dashed red line) by passive upwelling of the asthenosphere during the anelastic rebound of the continental margins around a spot rupture of the hyperextended lithosphere. The fully oceanic area is separated by the active rifting zone by strike-slip faults. A reference line (solid black) has been drawn to represent the state of deformation of the margins during the anelastic relaxation. The propagation of the rupture proceeds at higher velocity southwards, according to the direction of maximum extension with a northern Euler pole, determining an enlargement of the oceanic area. As soon as the continental break-up attains the adjacent oceanic region, the southernmost part of the rifting zone is not anymore constrained and can start free relaxation. At this point, movement along the strike-slip faults is inverted, while a new transcurrent line forms at the northern tip of the newly oceanic area.

\section{GEOPHYSICAL EVIDENCE OF POST-RIFT CONTRACTION}

Although the oldest mapped magnetic lineations in the Red Sea have an age $\mathrm{C} 3 \mathrm{y}(4.18 \mathrm{Ma})$, a recent accurate reexamination of 68 magnetic profiles from ship-track data in the Red Sea region (Schettino et al. 2016) has shown the existence of short-lived episodes of fast or ultra-fast spreading at the onset of seafloor spreading. In particular, our analysis has proved that in most cases the oldest anomalies identified on magnetic profiles are associated with strongly magnetized blocks of oceanic crust that formed at high spreading rates.

A selection of representative profiles from the southern, central and northern Red Sea is illustrated in Fig. 2, while the complete data set can be found in the supplementary material to Schettino et al. (2016). These data suggest that independently from the age of formation of the spreading segments, which in the case of the Red Sea decreases northwards, the initial stripes of oceanic crust after the break-up form at a rate that largely exceeds the far-field velocity of the conjugate plates. Consequently, the continental margin adjacent to a new spreading segment should experience post-rift contraction immediately after the rift-drift transition (Withjack et al. 1995;
Schlische et al. 2003), accompanied by inversion of the rift structures at the upper crustal scale. It is important to note that such post-rift contraction is a long-term (i.e. at geological times) process distinct from the well-known post-seismic viscoelastic relaxation, which operates over time lapses of years or decades (e.g. Bürgmann \& Dresen 2008; Wright et al. 2012).

Additional evidence for a short phase of contraction of the continental margins at the beginning of the post-rift period comes from the distribution of finite extensional strain along the Arabian and Nubian margins. Recently, Schettino et al. (2018) have determined the variability of the crustal stretching factor $\beta$ for the Red Sea margins by the analysis of 23 crustal profiles oriented as the flow lines of relative motion between Nubia and Arabia. These data, which are listed in the first six columns of Table 1, can be used to estimate the finite transversal strain, $\varepsilon_{y y}^{\prime}=\ln (\beta)$, and to perform a comparison of this quantity with the theoretical finite strain predicted by plate kinematics (Schettino et al. 2016):

$\varepsilon_{y y}(\zeta, t)=\ln \left[1-\frac{\omega_{0} R \sin (\zeta / R)}{L_{0}}\left(t-t_{0}\right)\right]$.

This quantity represents the amount of extensional strain at distance $\zeta$ from the Euler pole and time $t$, assuming a constant angular 


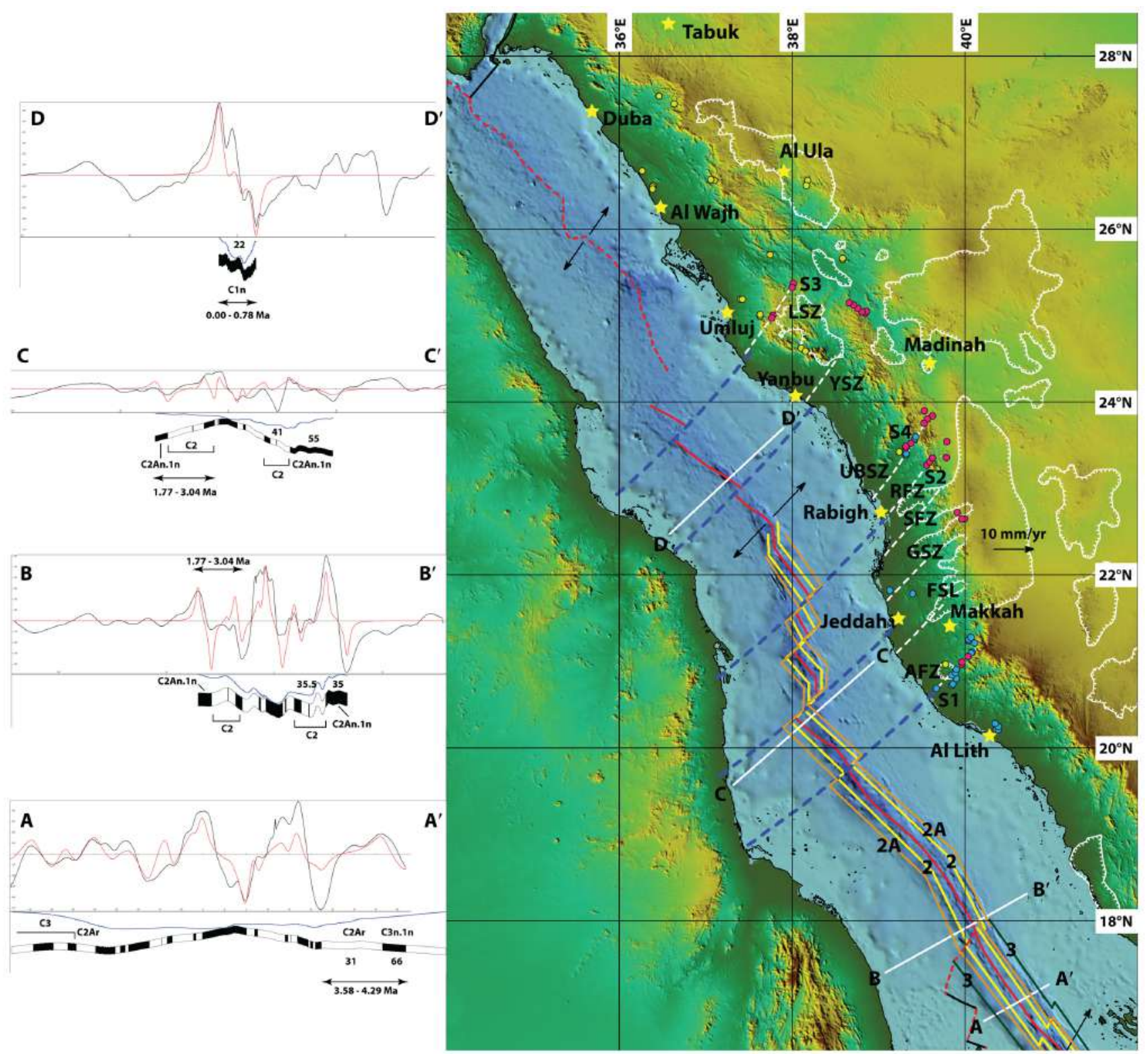

Figure 2. Topographic-bathymetric map of the central and northern Red Sea showing the traces of representative magnetic profiles (white lines) whose magnetization models reveal the initial fast pulse of seafloor spreading (insets). Numbers below the magnetized blocks are full spreading rates (in mm/yr). The red and black profiles are calculated and observed magnetic anomalies, respectively. The magnetic isochrons 2 (yellow), 2A (ocra) and 3 (dark green) are from Schettino et al. (2016), as well as fracture zones and transverse structures (dashed blue lines), rift axes (dashed red lines) and strike slip faults (black lines). Survey sites of the 2015 (yellow dots), Winter 2016 (red dots) and Fall 2016 (blue dots) campaigns are also shown. Dashed white lines show major tectonic lineaments. GSZ = Ghayth Shear Zone; SFZ = Samaran Fault Zone; RFZ = Rabigh Fault Zone; UBSZ = Umm al Birak Shear Zone; YSZ = Yanbu Shear Zone; LSZ = Lunayyir Shear Zone. White lines with barbs show the distribution of Cenozoic volcanic fields (harrats).

velocity of rifting $\omega_{0}$ from the initial time $t_{0}$ and an initial width of the rift given by $L_{0}$. In eq. (1), the parameter $R$ is the Earth's radius. Plots of the kinematic and observed strains are shown in Fig. 4, while the estimated values of kinematic strain, $\varepsilon_{y y}$, and recovered strain, $\delta \varepsilon_{y y}$, are listed in Table 1, where we have assumed that rifting started at $t_{0}=27 \mathrm{Ma}$ (Schettino et al. 2018) and was substituted by seafloor spreading at the time $t_{f}$ listed in the table. The results shown in Fig. 4 represent the strongest evidence that part of the extensional strain accumulated along the continental margins is recovered after the onset of seafloor spreading. In fact, these plots show that the curves of kinematic and observed strain practically coincide in the northern Red Sea area, where active rifting is still ongoing. Conversely, the two curves are separated by a quantity that increases with the distance from the Euler pole (and the age of the oceanic crust) in the central and southern Red Sea region. The difference between theoretical (kinematic) and observed strain is interpreted as a recovered strain that was originally accumulated during the rifting phase. The plot in Fig. 4 shows that this quantity attains a value of $\sim 0.23$ at $\sim 19.9^{\circ} \mathrm{N}$ and remains approximately constant south of this latitude. Therefore, the maximum recovered strain along the Red Sea continental margins of Nubia and Arabia is $\sim 38$ per cent of the total kinematic strain.

The distribution of finite strains in the central and northern Red Sea (Fig. 4 and Table 1) suggests that the post-rift deformation of 

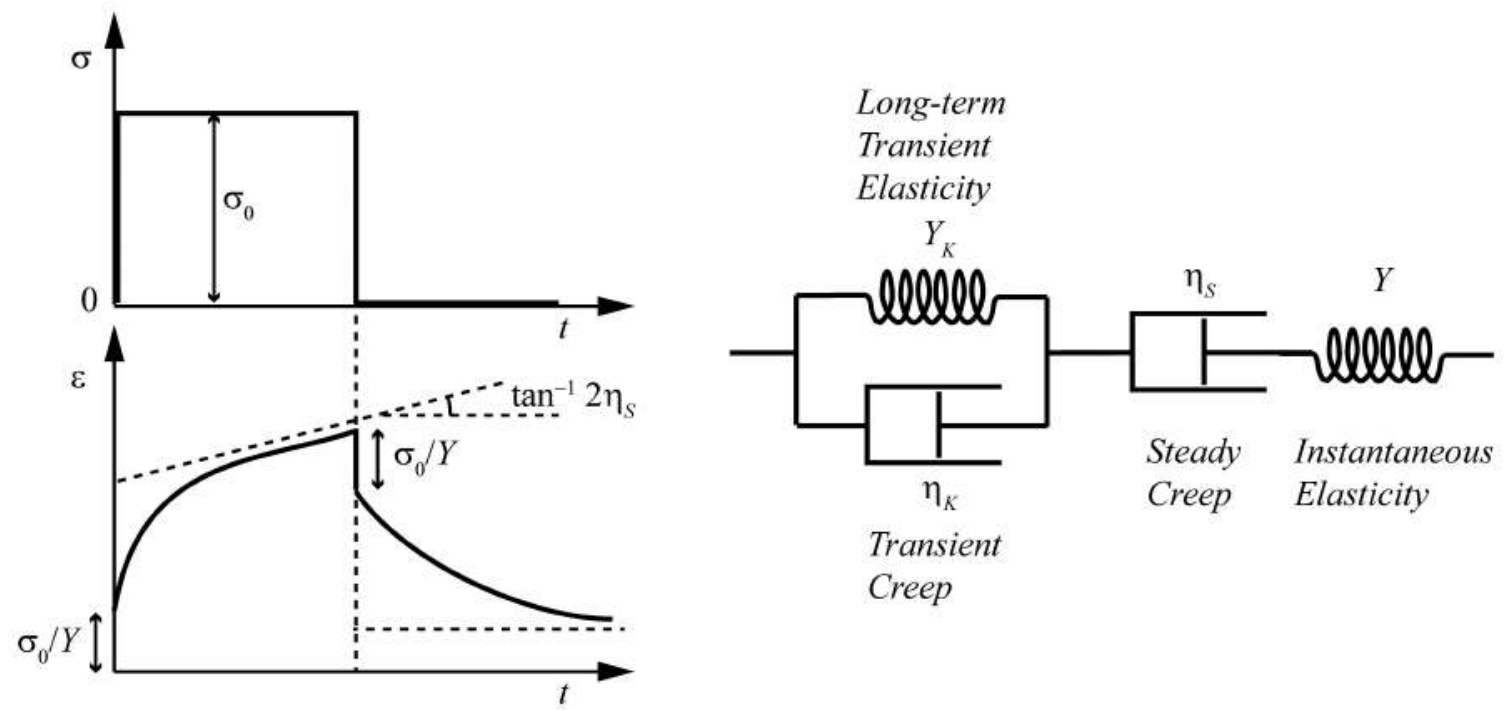

Transient

Creep

Figure 3. Analogue model for the Burgers rheology. $\sigma_{0}$ is the applied stress, $\varepsilon$ is the corresponding strain, $Y_{K}$ and $\eta_{K}$ are the transient anelastic modulus and viscosity, respectively, while $Y$ and $\eta_{S}$ represent the instantaneous elastic modulus and steady-state viscosity, respectively.

Table 1. Finite strains across the central and northern Red Sea.

\begin{tabular}{|c|c|c|c|c|c|c|c|c|c|c|}
\hline$N^{\mathrm{a}}$ & $\zeta^{b}$ & $\lambda^{c}$ & $L^{e}$ & $L_{0}{ }^{\mathrm{f}}$ & $\beta^{d}$ & $\varepsilon_{y y}^{\prime}{ }^{g}$ & $t_{f}^{\mathrm{i}}$ & $\varepsilon_{y y}{ }^{h}$ & $\delta \varepsilon_{y y}{ }^{j}$ & $\delta \varepsilon_{y y} / \varepsilon_{y y}{ }^{k}$ \\
\hline 1 & 1855 & 18.29 & 704 & 493 & 1.4284 & 0.3565 & 4 & 0.5819 & 0.2254 & 0.39 \\
\hline 2 & 1811 & 18.62 & 694 & 493 & 1.4068 & 0.3413 & 4 & 0.5713 & 0.2300 & 0.40 \\
\hline 3 & 1767 & 18.92 & 707 & 507 & 1.3943 & 0.3324 & 4 & 0.5492 & 0.2168 & 0.39 \\
\hline 5 & 1677 & 19.50 & 664 & 475 & 1.3976 & 0.3347 & 4 & 0.5552 & 0.2205 & 0.40 \\
\hline 6 & 1633 & 19.86 & 590 & 398 & 1.4811 & 0.3928 & 4 & 0.6220 & 0.2292 & 0.37 \\
\hline 7 & 1589 & 20.12 & 609 & 408 & 1.4942 & 0.4016 & 4 & 0.5993 & 0.1977 & 0.33 \\
\hline 10 & 1456 & 21.57 & 626 & 442 & 1.4162 & 0.3480 & 4 & 0.5275 & 0.1795 & 0.34 \\
\hline 11 & 1412 & 22.08 & 795 & 541 & 1.4700 & 0.3853 & 3 & 0.4542 & 0.0689 & 0.15 \\
\hline 12 & 1367 & 22.50 & 811 & 520 & 1.5589 & 0.4440 & 2 & 0.4719 & 0.0279 & 0.06 \\
\hline 13 & 1323 & 22.78 & 678 & 474 & 1.4291 & 0.3571 & 2 & 0.4949 & 0.1378 & 0.28 \\
\hline 14 & 1279 & 23.13 & 795 & 536 & 1.4838 & 0.3946 & 1 & 0.4513 & 0.0566 & 0.13 \\
\hline 15 & 1235 & 23.35 & 760 & 516 & 1.4721 & 0.3867 & 1 & 0.4522 & 0.0655 & 0.14 \\
\hline 20 & 1013 & 25.58 & 736 & 481 & 1.5287 & 0.4244 & 0 & 0.4209 & -0.0036 & -0.01 \\
\hline 21 & 968 & 25.86 & 750 & 500 & 1.5009 & 0.4061 & 0 & 0.3934 & -0.0127 & -0.03 \\
\hline 22 & 924 & 26.17 & 751 & 520 & 1.4446 & 0.3678 & 0 & 0.3663 & -0.0016 & 0.00 \\
\hline 23 & 880 & 26.58 & 804 & 589 & 1.3648 & 0.3110 & 0 & 0.3162 & 0.0052 & 0.02 \\
\hline
\end{tabular}

${ }^{\mathrm{a}} N=$ profile number.

$\mathrm{b}_{\zeta}=$ distance from the Euler pole $(\mathrm{km})$.

${ }^{\mathrm{c}} \lambda=$ latitude of Red Sea axis intersection $\left(^{\circ}\right)$.

$\mathrm{d} \beta=\beta$ factor.

${ }^{\mathrm{e}} L=$ rift width $(\mathrm{km})$.

${ }^{\mathrm{f}} L_{0}=$ initial width of the rifting area $(\mathrm{km})$.

$\mathrm{g}_{\mathcal{E}^{\prime}{ }_{y y}^{\prime}}=$ observed transversal strain.

$\mathrm{h}_{\varepsilon_{y y}}=$ kinematic strain.

${ }^{\mathrm{i}}{ }_{t_{f}}=$ time of initiation of seafloor spreading (Ma).

$\mathrm{j}_{\delta \varepsilon_{y y}}=$ recovered strain $\left(=\varepsilon_{y y}-\varepsilon^{\prime}{ }_{y y}\right)$.

${ }^{\mathrm{k}} \delta \varepsilon_{y y} / \varepsilon_{y y}=$ percentage of recovered strain $\left(=1-\varepsilon^{\prime}{ }_{y y} / \varepsilon_{y y}\right)$.

the Nubia and Arabia continental margins could have ceased between $\sim 19.9^{\circ} \mathrm{N}$ and the North Danakil triple junction at $\sim 18^{\circ} \mathrm{N}$. Also, these data support the hypothesis that strain recovery is still ongoing between $\sim 19.9^{\circ} \mathrm{N}$ and $\sim 24^{\circ} \mathrm{N}$. In our view, it is not a coincidence that the latter value coincides with the northernmost latitude where a spreading centre is disclosed by the analysis of marine magnetic anomalies (Schettino et al. 2016). Therefore, we expect that a noticeable amount of seismic release affects this area, 


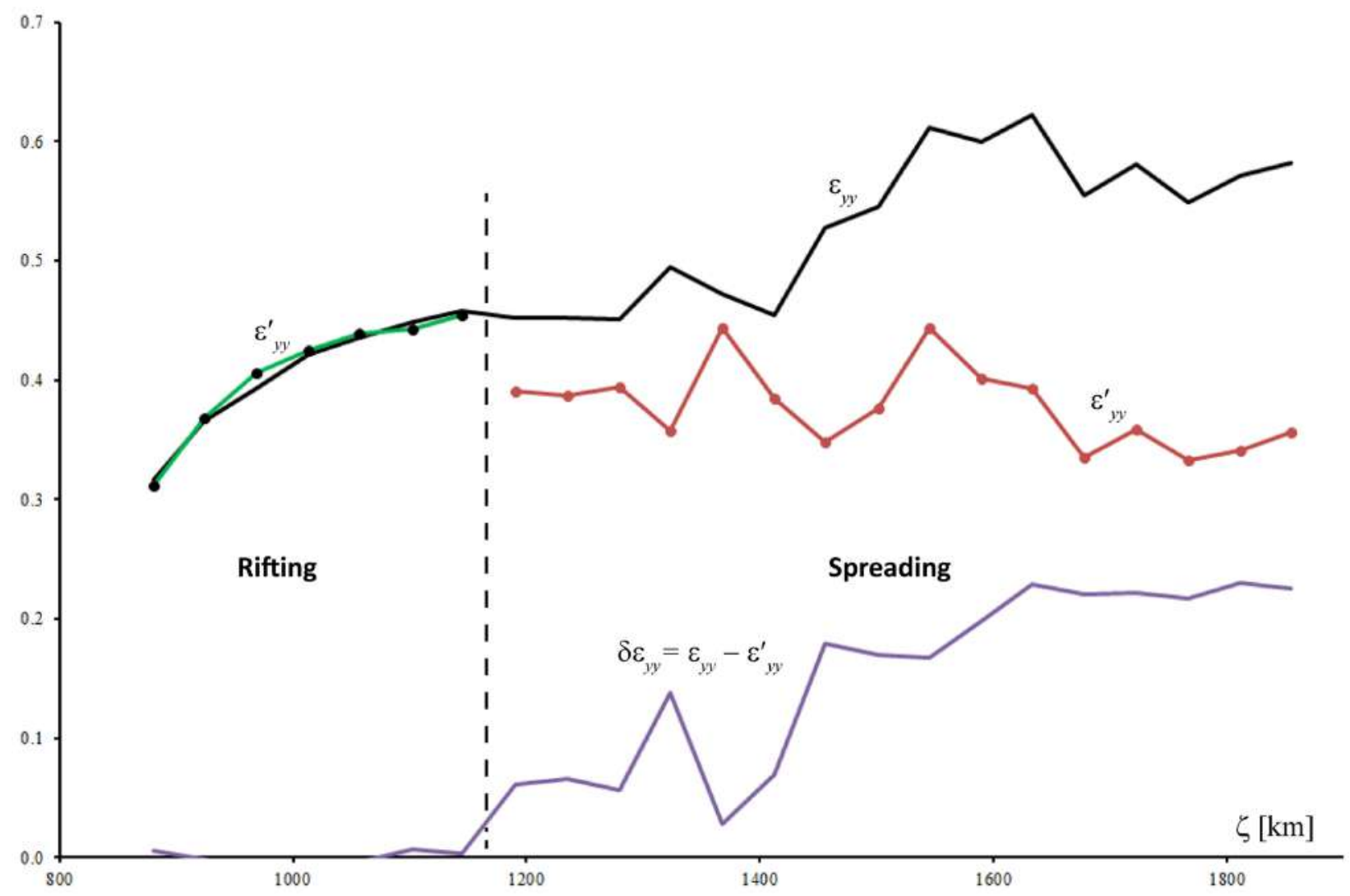

Figure 4. Distribution of strain along the Red Sea margins. Black line: kinematic strain as a function of the distance $\zeta$ from the Euler pole of relative motion between Nubia and Arabia; red line: finite transversal strain, obtained from observed $\beta$ factors, along the passive continental margins facing the oceanized region of the Red Sea; green line: finite transversal strain along the active rifting region of the northern Red Sea; violet line: recovered strain.

distinctly from the syn-rift seismicity of the northern Red Sea region, and that the continental margins south of $\sim 19.9^{\circ} \mathrm{N}$ display only a normal background seismicity, typical of stable tectonic plate interiors. The spatial distribution of 28025 epicentres of earthquakes from the ISC catalogue (International Seismological Centre, On-line Bulletin, http:/www.isc.ac.uk, Internatl. Seismol. Cent., Thatcham, United Kingdom, 2015) for the Red Sea region and surrounding areas since 1964 is shown in Fig. 5. We note the relevant seismicity of the areas of active rifting north of $\sim 24^{\circ} \mathrm{N}$ and in the southernmost Red Sea between the Danakil Horst and Yemen. For the remaining regions around the oceanic zone, the recognition of ongoing active deformation within the passive continental margins can be achieved mapping the spatial density of seismic events, independently from their magnitude, in the direction of flow lines of relative motion. To this purpose, we defined 92 statistical bins bounded by flow lines determined on the basis of the plate kinematics model of Schettino et al. (2016) and by the rift shoulders (Fig. 5). Because of the strong asymmetry of the Red Sea rift, only the Arabian Plate margin was considered. For each bin, we counted the number of events along the continental margin, taking epicentral data between the oldest magnetic isochrons and the $1000 \mathrm{~m}$ topographic contour. In the areas of recent spreading ridge formation, we considered only events located at least $5 \mathrm{~km}$ away from the ridge axis, taking into account that this is the average distance of the continental margin from the axial zone after $1 \mathrm{Myr}$ at $10 \mathrm{~mm} \mathrm{yr}^{-1}$ full spreading rate. The distribution of seismicity associated with this set of bins is illustrated in Fig. 6 . In terms of latitudes at which the bins intersect the spreading ridge, four areas of significant tectonic activity can be defined, respectively between $23.13^{\circ} \mathrm{N}$ and $23.55^{\circ} \mathrm{N}$ in the northern sector, between $20.04^{\circ} \mathrm{N}$ and $21.08^{\circ} \mathrm{N}$ in the central Red Sea, between $17.25^{\circ} \mathrm{N}$ and $18.14^{\circ} \mathrm{N}$ and between $15.26^{\circ} \mathrm{N}$ and $16.53^{\circ} \mathrm{N}$ in the southern Red Sea. All these areas display a significant mean number of events per bin. The northernmost and southernmost of them are located close to the northern and southern boundary of the oceanic areas, respectively, where localized axial extension along the spreading ridge is replaced by active rifting and diffuse deformation ( $c f r$. Fig. 1). In particular, the southernmost zone of deformation includes the well-known seismic zone of Jizan, Saudi Arabia, characterized by strong events associated with right-lateral strike-slip deformation (Zahran et al. 2016; Abdelfattah et al. 2017). This seismicity can be only explained assuming that the axial zone south of $15.26^{\circ} \mathrm{N}$ is not fully oceanic. Actually, the magnetic data of Schettino et al. (2016) include only two crossings $\mathrm{C} 1 \mathrm{n}$ in this area, which could be representative of isolated oceanic cells, while the pattern of seismicity is compatible with the diffuse seismicity of a rift valley.

Two intermediate zones of elevated seismicity are also shown in Figs 5 and 6. The northernmost of these areas is located in the central Red Sea, where the spreading ridge assumes a strongly segmented shape (Fig. 5). The seismicity of this area, which includes the continental margin of Arabia in the Jeddah-Makkah region, has been studied by several authors (e.g. Al-Saud 2008; Fnais et al. 2015; Zahran et al. 2016). Basically, it is characterized by dextral strike-slip motion along major shear zones, such as the Ad Damm Fault and the Fatima Structural Lineament (FSL; Fig. 2). South of the Jeddah-Makkah region, there is a wide zone characterized by 


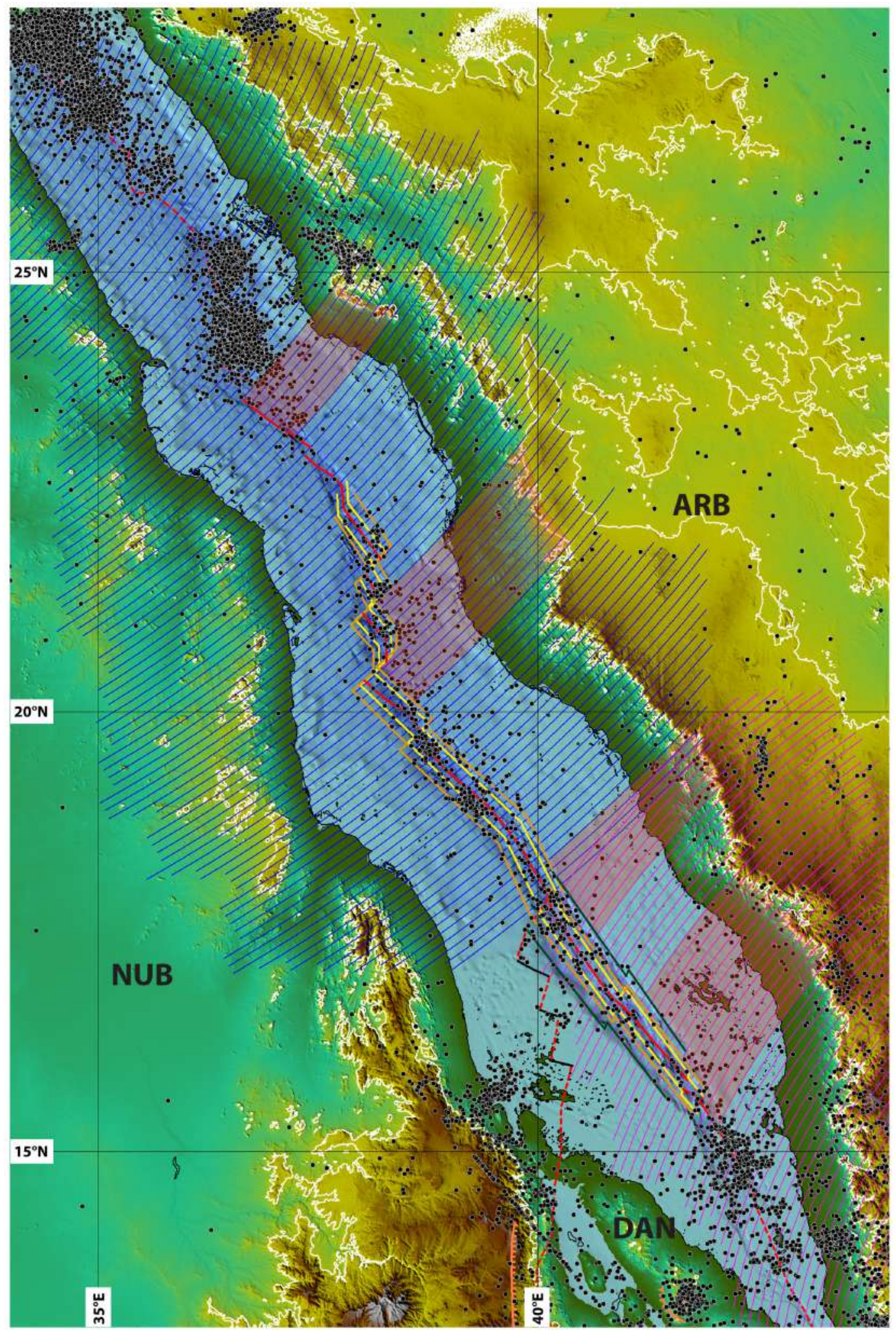

Figure 5. Seismicity along the Red Sea margins. Dots represent earthquake epicentres from the ISC catalogue (1964-2018). The Nubia-Arabia (blue lines) and Arabia-Danakil (violet lines) flow lines of recent motion (Schettino et al. 2016) have been used to define bins for an evaluation of active deformation along the Arabian margin. NUB = Nubia, $\mathrm{ARB}=$ Arabian plate, $\mathrm{DAN}=$ Danakil. The white line represents the $1000 \mathrm{~m}$ topographic contour. The transparent reddish areas represent zones of elevated seismicity along the passive margin of Arabia. 


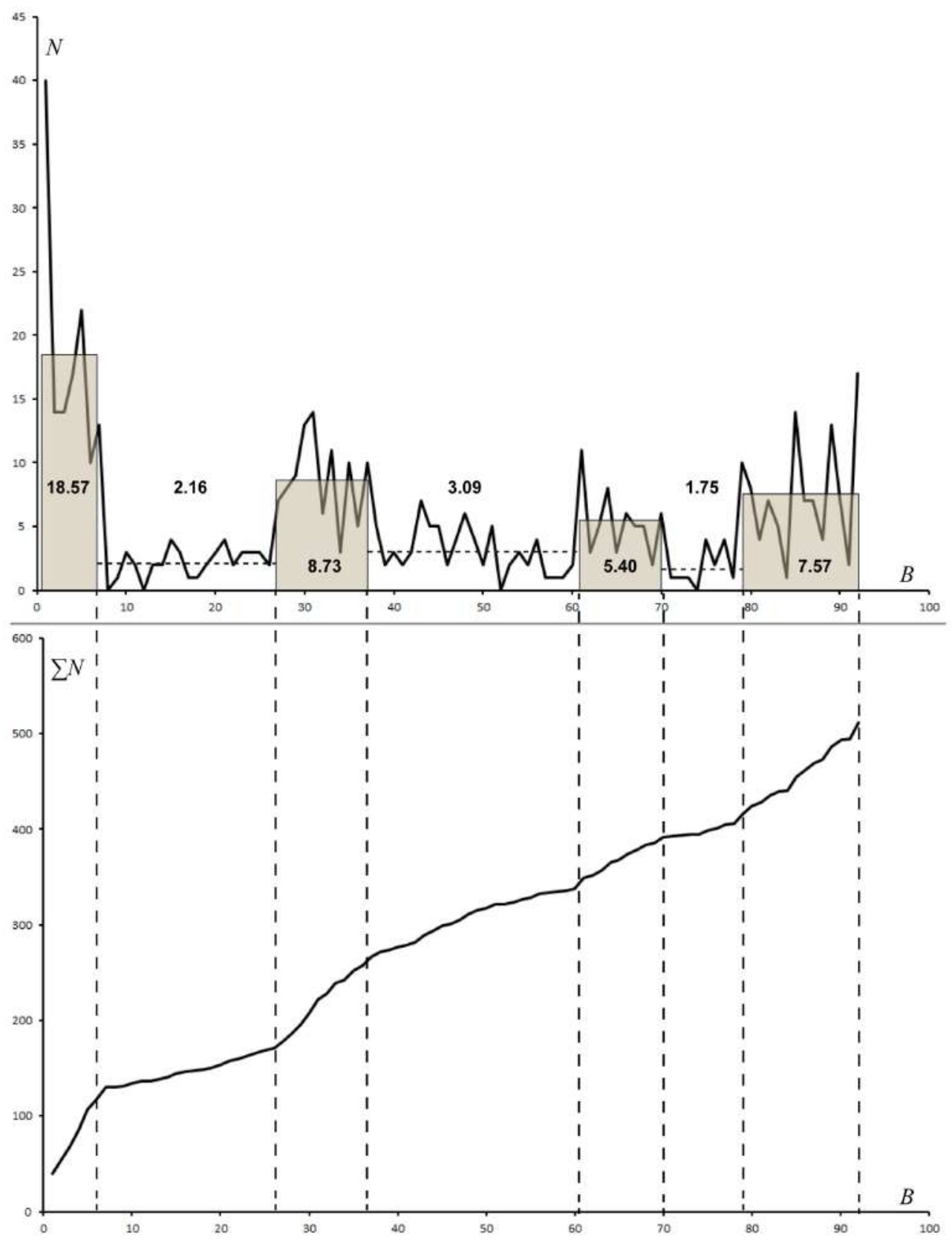

Figure 6. Top: number of seismic events $(N)$ in statistical bins oriented as the flow lines of relative motion. $B$ is a progressive bin number, starting from the northernmost one. The shaded areas represent regions of elevated seismicity. Numbers indicate the average number of events per bin. Bottom: cumulative plot of the number of earthquakes. The ramps of this plot correspond to intervals of high seismicity.

low seismicity, in agreement with the strain recovery pattern shown in Fig. 4. The average number of events per bin increases again in proximity of the triple junction between Arabia, Nubia, and Danakil at $\sim 18^{\circ} \mathrm{N}$, where plate kinematics predicts right-lateral transpressional deformation along the Arabian margin. Farther south, the seismicity decreases again to a background level in the areas surrounding the oldest oceanic lithosphere (up to 4.6 Ma).

\section{GEOLOGICAL EVIDENCE OF TECTONIC INVERSION}

Fieldwork was carried out during three successive geological campaigns across a wide area of the Arabian margin between the provinces of Makkah and Tabuk in 2015 and 2016 with the support of the Saudi Geological Survey (SGS). The focus of this survey was the Cenozoic fault pattern and a comparison of shear zone kinematics with the predictions of regional plate motion models. A preliminary analysis of the fault zones was carried out on the basis of morpho-structural lineaments detected on satellite images. Here we will describe some significant examples of field structures associated with the post-rift inversion tectonics. The location of the studied sites for these campaigns is shown in Fig. 2, while Figs 7-11 illustrate examples of outcrop-scale features at selected sites.

The first important example of a shear zone associated with postrift tectonics is the AFZ (Figs 2 and 7), which intersects Precambrian metagranitoids of the Naman complex. This fault zone trends 


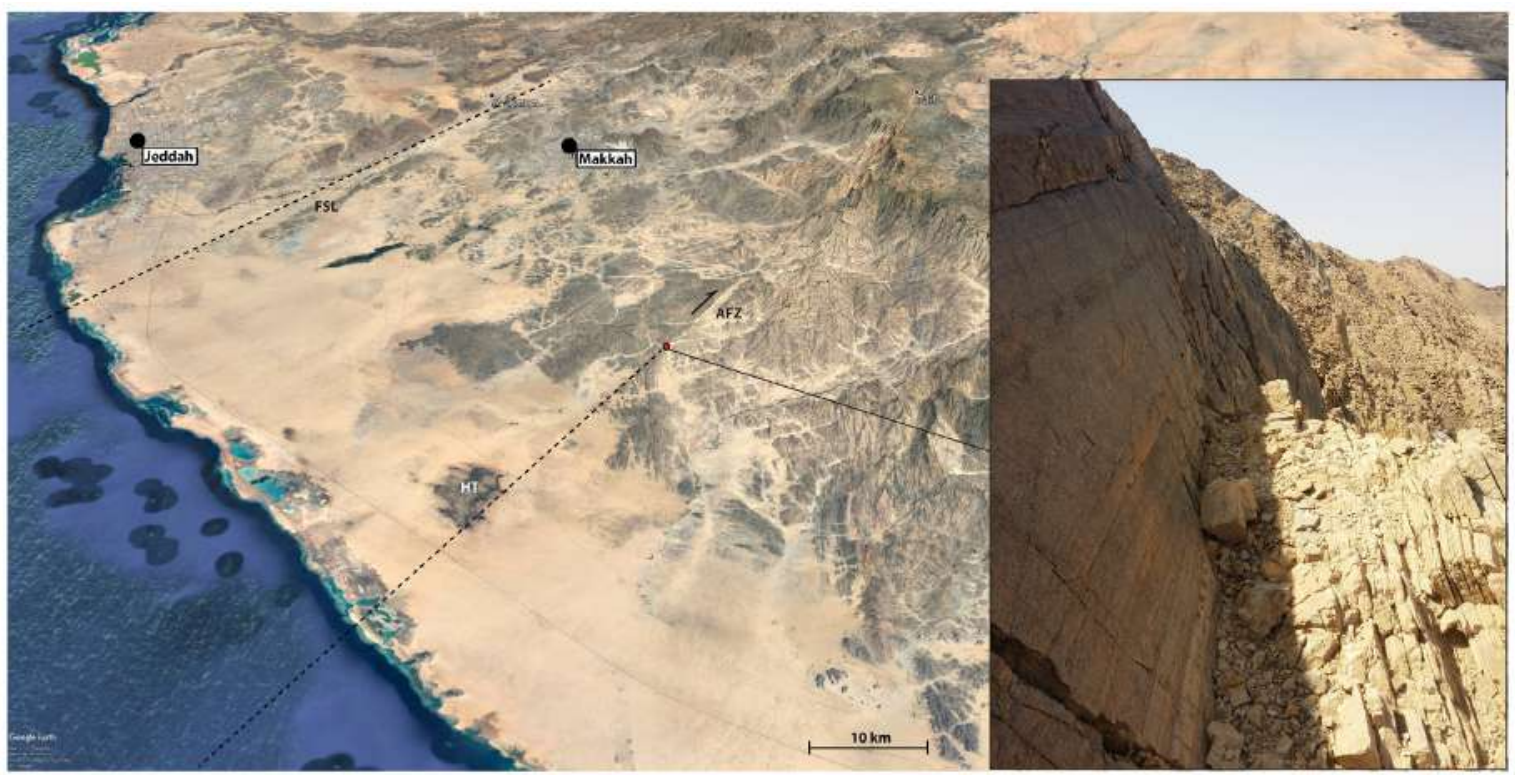

Figure 7. Spectacular Google Earth view of the Ad Damm Fault Zone and the Fatima Structural Lineament, along the Arabian margin of the central Red Sea. These are inherited Precambrian structures, reactivated as right-lateral strike-slip faults during post-rift tectonics (Al-Saud 2008; Fnais et al 2015; Schettino et al. 2016). Dashed lines are the assumed prolongations of these major transcurrent faults towards existing fracture zones of the central Red Sea. The dextral displacement of the northern sectors is compatible with the northward migration of the Red Sea ridge (see Fig. 1). The inset shows a representative site along the AFZ where kinematic indicators of the current right-lateral strike-slip motion are very clear.

NNE-SSW, deeps steeply, and bears shallow plunging quartz fibres or striae that indicate dextral movement with a weak reverse component (Fig. 7). Such brittle structure reactivates ductile shear zones that could be Neoproterozoic in age (e.g. Hamimi et al. 2014). This fault, together with the Fatima fault (Fig. 7), represents an important example of Proterozoic structure reactivated as a right-lateral strike-slip fault during the Red Sea post-rift stage. It also provides strong evidence of inversion tectonics on several transversal structures along its northern side. A very significant example can be found at Harrat Tafil, $\sim 15 \mathrm{~km} \mathrm{NE}$ of the coastline and $\sim 100 \mathrm{~km}$ SE of Jeddah (site S1 in Fig. 2). Here a system of folds and inverse faults affects Miocene stratified volcanoclastic rocks of the Sita Formation (Fig. 8). The folding has generated an antiform that is characterized by a shallow plunging axis trending at $150^{\circ} \mathrm{N}$, suggesting a NE vergence, according to the short limb being towards NE (Fig. 8a). The vergence is in agreement with the NE direction of contraction of the region to the north of the Ad Damm fault. Reverse faulting affects the antiform limbs and could result from strain localization (Fig. 8b). This faulting is characterized by NWSE and NNW-SSE trends with fault lineation plunging towards the ENE and SW. Pliocene volcanics of the HT ( $23.25 \mathrm{Ma}$; Pallister 1983) cover the Miocene rocks of the Sita Formation. According to Pallister (1983), the folded rocks of the Sita Formation are unconformably overlain by non-folded Pliocene volcanics. Consequently, the deformation should be older than $\sim 3.25 \mathrm{Ma}$ and younger than $19 \mathrm{Ma}$, which is the age of the folded rocks according to Pallister (1983).

Another example of reverse faulting can be observed at Wadi Far' (site S2 in Fig. 2) near the A1 Madiq village (Fig. 9a). These are N-S trending faults in Precambrian andesite rocks. S-C-type structures (e.g. Passchier \& Trouw 2005), as well as calcite fibres, are very common and indicate the reverse slip (Figs 9b and c), locally associated with a dextral component. Locally these faults produced metre-thick cataclastic bands. A NE-SW trending steep dextral fault system, subparallel to the Wadi Far', is visible for some kilometres along the wadi and, besides andesites, also intersects Precambrain granitoids. Shallow plunging slickensides indicate dextral strike slip and are locally overprinted by rare sinistral kinematic indicators that are preserved in andesites. This observation seems to confirm the hypothesis of kinematic inversion along major strike-slip faults illustrated in Fig. 1.

Another system of transversal reverse faults associated with a major shear zone affects felsic volcanic rocks of the Neoproterozoic Fashghah formation (Fig. 10A), nearby the northwestern ridge of Jabal Rayyan (Site S3 in Fig. 2). The NNE-SSW trending dextral strike-slip fault is not pervasively recorded and it ends into a NNW-SSE trending reverse fault, evidenced by S$\mathrm{C}$ structures (Figs $10 \mathrm{a}-\mathrm{c}$ ). The reverse faulting is responsible for decimetre-thick cataclastic bands (Fig. 10d). This site shows very clearly the synergistic relationship between transcurrent and reverse faults during the post-rift contraction of the continental margins. In fact, the dextral strike-slip fault in Fig. 10, which will be referred to as the Lunayyir Shear Zone (LSZ), represents the southern boundary of a part of the Arabian continental margin facing the most recent spreading segment in the northern Red Sea (Fig. 2). According to the theoretical model illustrated in Fig. 1, the southern part of this area, in proximity of the LSZ, should experience the maximum rate of post-rift contraction in modern times.

The last example of a NNE-SSW trending dextral strike slip fault, associated with NW-SE trending reverse faults, is illustrated in Fig. 11. The Umm al Birak Shear Zone (UBSZ) is an inherited fault that intersects the E-W trending Wadi Fadjah northeast of the Umm al Birak village (Fig. 11d). This shear zone affects Neoproterozoic intrusive rocks of the Bustan complex and volcanics of the Suri formation. An example of inverse faulting in the area just north of the strike-slip fault, evidenced by $\mathrm{S}-\mathrm{C}$ structures, is shown in Figs $11 \mathrm{~b}$ and c (site S4 in Fig. 2). Dextral strike-slip motion along the UBSZ is documented by shallow plunging striations of fault surfaces (Fig. 11f) and by dextral transpressive push-up structures 


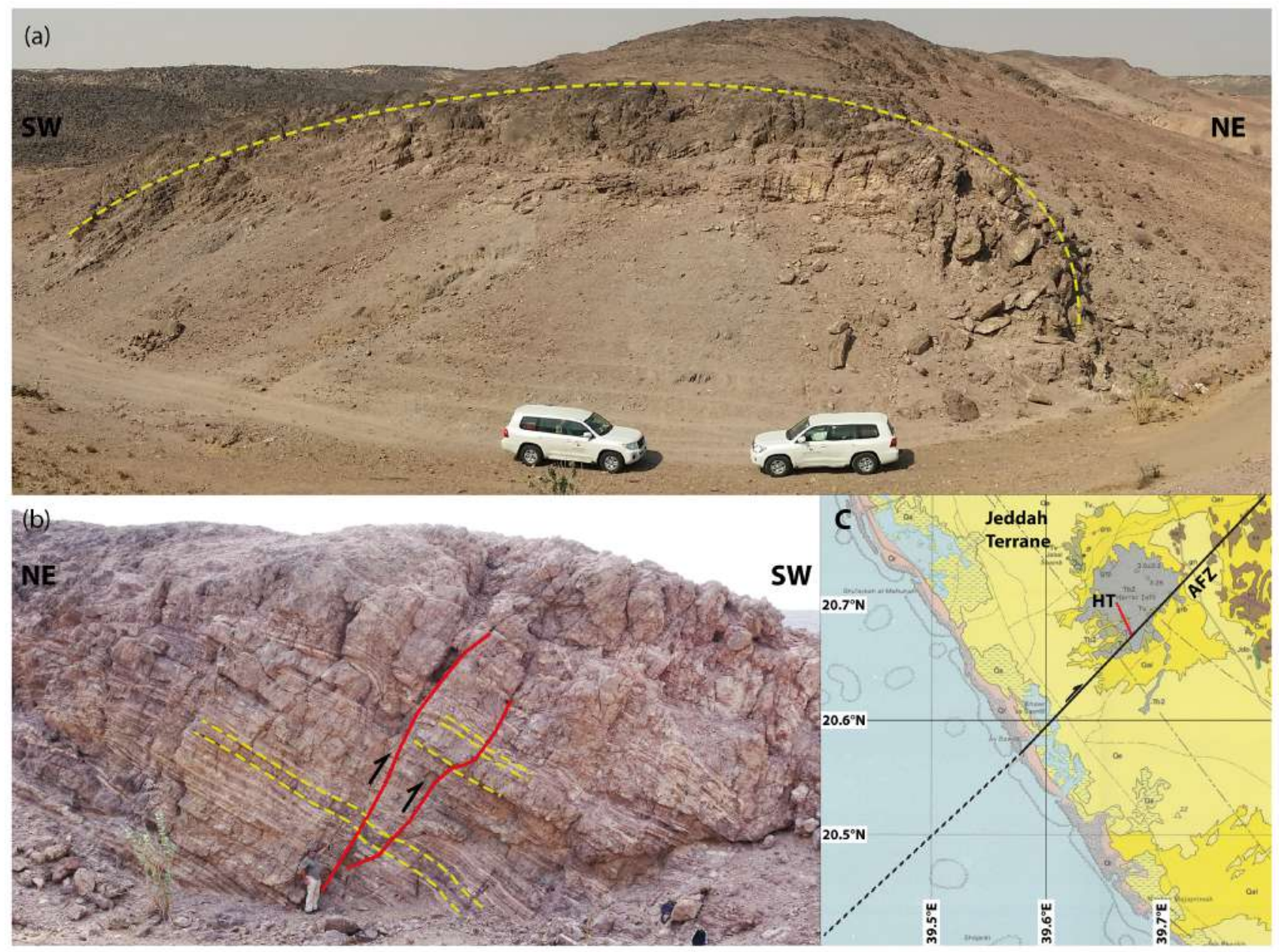

Figure 8. (a) Macro-scale folding of Miocene strata at Harrat Tafil (HT), Saudi Arabia (site S1 in Fig. 2). (b) Reverse faults superimposed on the main antiform flank. Syn-sedimentary slumping folds are also visible. (c) Location map of HT (Pallister 1983). The red line indicates the macro-anticline fold axis. AFZ = Ad Damm Fault Zone.

developed where the fault line strike decreases with respect to the main trend (Figs $11 \mathrm{e}-\mathrm{g}$ ).

\section{A SIMPLIFIED RHEOLOGICAL MODEL OF THE LITHOSPHERE IN CONTINENTAL RIFTS}

The geophysical and geological evidence presented in the previous sections supports the hypothesis that the thinned continental margins are subject to a short phase (a few million years) of contraction after the onset of seafloor spreading. This process implies that part of the extensional strain that develops during the rifting stage is accumulated in the mantle lithosphere and can be recovered by anelastic relaxation at the beginning of the subsequent post-rift phase. Therefore, extra space is created in the axial zone at the onset of seafloor spreading, driving an excess production of oceanic crust by increased passive asthenosphere upwelling, accompanied by inverse faulting and folding along the margins. In the next sections, we will present a rheological explanation for this behaviour, based on the assumption that the transient behaviour of the lithosphere can be modelled as a Kelvin-Voigt body.

We will consider both a classical linear Kelvin-Voigt rheology and a non-linear Kelvin model to explore the tenability of anelastic relaxation as a driving mechanism for the observed phase of post-rift contraction of the continental margins accompanied by a fast pulse of seafloor spreading. Anelastic relaxation in the mantle has been shown to account for a range of processes from seismic wave attenuation to glacioisostatic rebound (cf. the review by Faul \& Jackson 2015). Both the seismic quality factor $Q$ and the steadystate viscosity of peridotite depend on homologous temperature (Sato 1991), and rheological models with a transient component are compatible with postglacial relative sea level data and a mantle with a bulk transient rheology (Müller 1986). Here, we hypothesize that a residual (asymptotic) transient component can last a few million years if the viscosity of the Kelvin-Voigt component is non-linear. Although the model is purely phenomenological, microphysical mechanisms accounting for strain energy dissipation and transient creep are available, and include diffusionally assisted grain boundary sliding, dislocations and presence of melt (Faul \& Jackson 2015).

We use olivine creep parameters, since in our hypothesis extensional strain accumulates during the rifting stage in the lithospheric mantle and is partially released at the beginning of the subsequent post-rift phase, while the crust participates in this process only passively. In order to cover a range of possibilities, we consider both dry and wet olivine creep parameters, because laboratory observations 


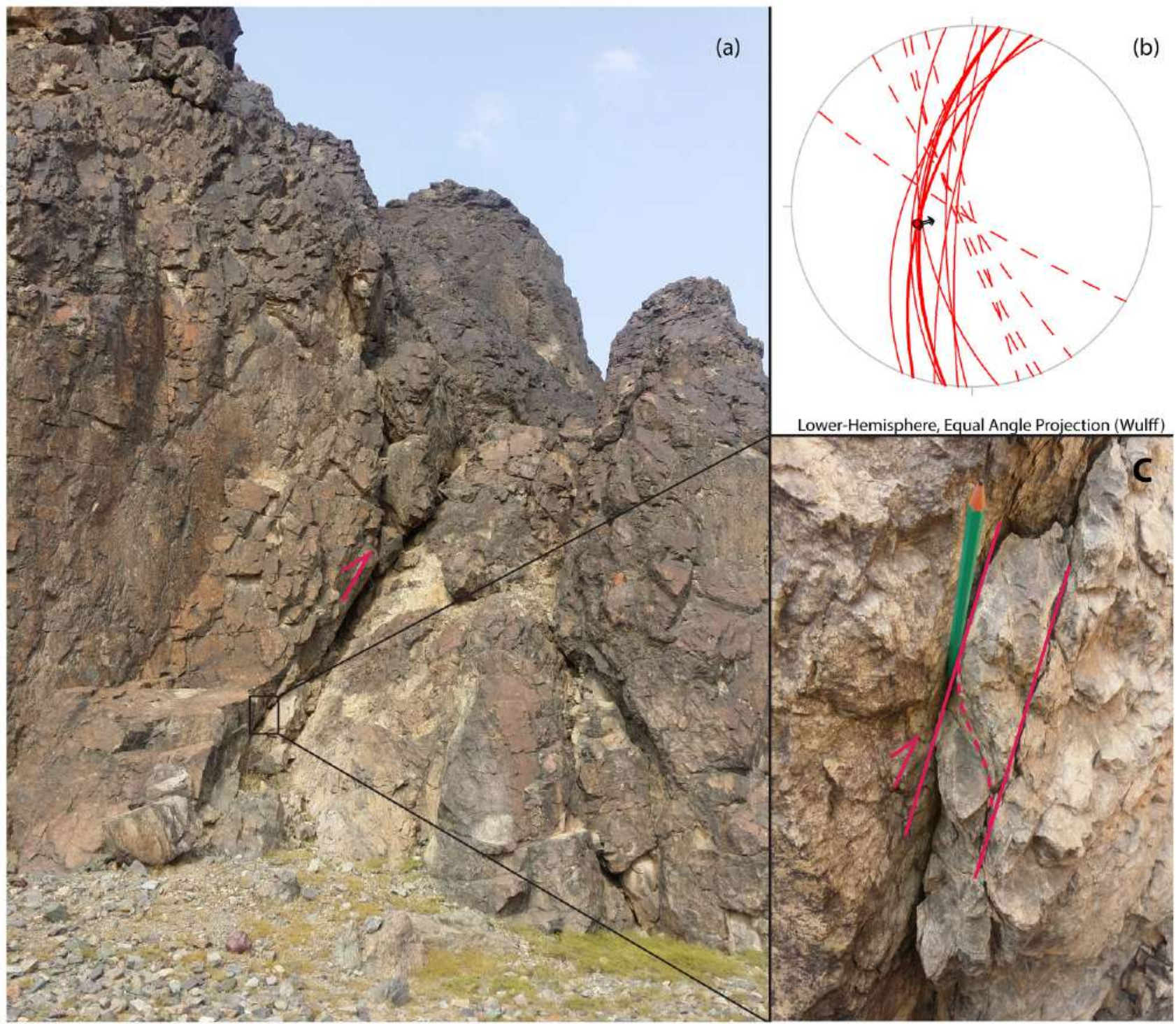

Figure 9. (a) A reverse fault with clear morphological evidence of recent activity at site S2 of Fig. 2. (b) Stereographic projection of S (dashed lines)-C (solid lines) structure related to the reverse fault. (c) Close-up on reverse S-C structures.

show that the subcontinental (and suboceanic as well) upper mantle rheology ranges between dry and wet (volatile-rich) conditions (Karato \& Wu 1993).

\subsection{Linear Kelvin rheology}

The constitutive rheological equation of a linear Kelvin body can be written as follows:

$\sigma=Y_{K} \varepsilon+2 \eta_{K} \dot{\varepsilon}$

where $\sigma$ is the stress, $\varepsilon$ is the strain, $Y_{K}$ is the anelastic relaxation modulus, and $\eta_{K}$ is the anelastic viscosity. For a stress pulse, such that $\sigma(t)=\sigma_{0}$ for a time interval $0 \leq t \leq t_{0}$ and assuming the initial condition $\varepsilon(0)=0$, we have the following solution for the loading phase:

$\varepsilon(t)=\frac{\sigma_{0}}{Y_{K}}\left(1-\mathrm{e}^{-\mathrm{t} / \tau}\right)$, where $\tau \equiv 2 \eta_{K} / Y_{K}$ is the Kelvin relaxation time. Similarly, the unloading curve can be determined assuming the initial condition $\varepsilon(0)=\varepsilon_{0}$ and setting $\sigma(t)=0$. We have for the strain rate:

$\dot{\varepsilon}(t)=-\left(\varepsilon_{0} / \tau\right) e^{-t / \tau}$.

Here we will assume the following parameters: initial strain $\varepsilon_{0}=1$, anelastic viscosity $\eta_{K} \cong 0.1 \eta_{S}=10^{21} \mathrm{~Pa} \mathrm{~s}, \eta_{S}$ being the steady-state viscosity associated with long-term creep of the lithospheric mantle, $Y_{K}=15-45 \mathrm{GPa}$. This relation between $\eta_{K}$ and $\eta_{S}$ has been proposed in the case of the transient viscosity of the asthenosphere, which can be estimated by a combination of GPS measurements of post-seismic surface motions and GRACE satellite measurements of gravity (Pollitz 2003, 2005; Freed et al. 2010, 2012; Panet et al. 2010; Hoechner et al. 2011). A difference of two orders of magnitude has been proposed for the mantle wedge above the Sumatran subduction zone (Qiu et al. 2018). Both methods provide an estimate of post-seismic deformation, respectively by the analysis of plate velocity fields and by the study of geoid variations associated with mass displacements. These studies adopted 


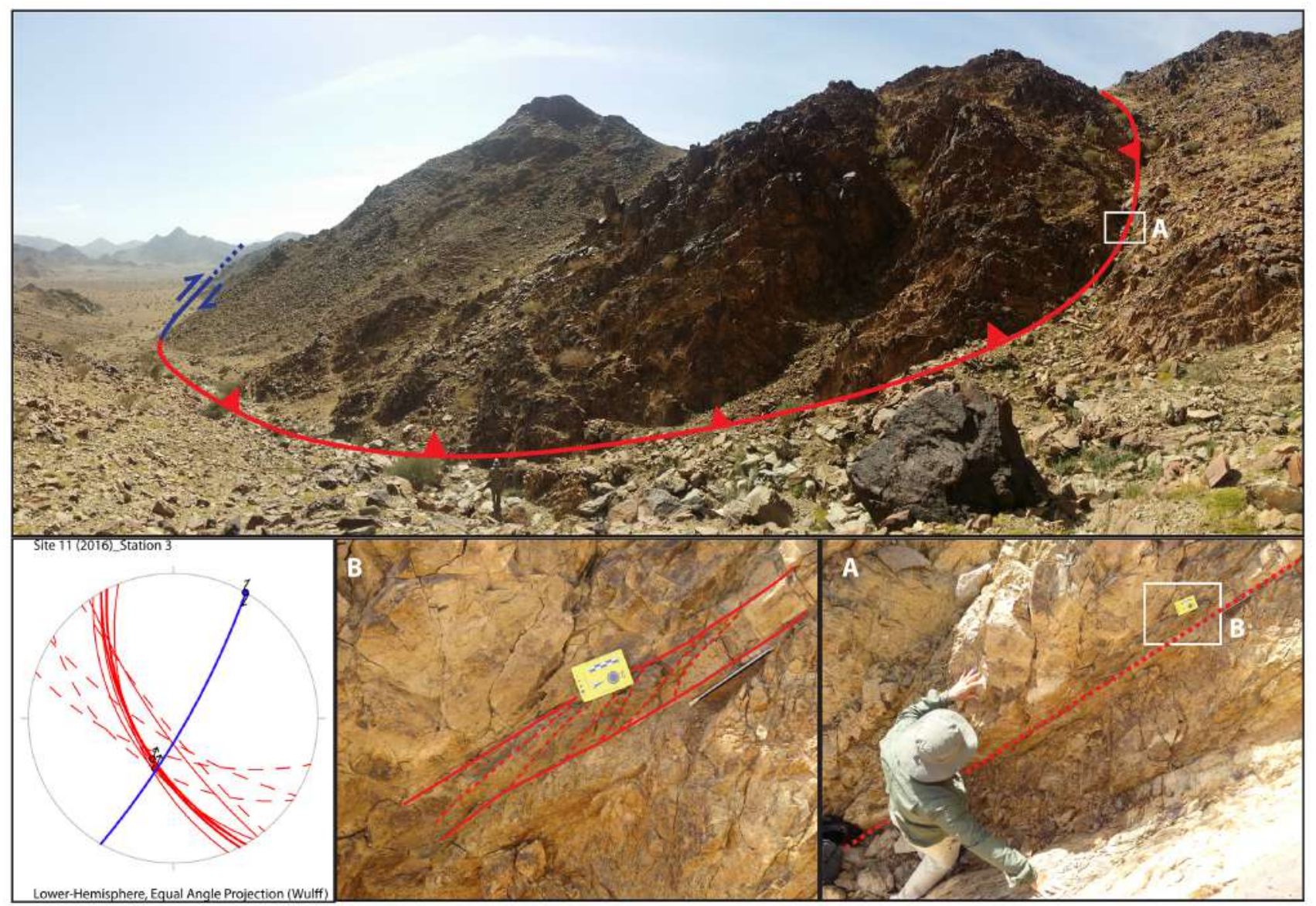

Figure 10. Top: a reverse fault with geomorphological evidence of recent activity at site $\mathrm{S} 3$ of Fig. 2, associated with a major dextral strike-slip fault. Bottom left: stereographic projection of the S-C structures related to the reverse fault (red; C = solid lines; $\mathrm{S}=$ dashed lines; striae $=$ red dots) and strike-slip fault (blue; main fault = solid line; striae = blue dot). (a) Decimetre-thick cataclastic band related to the reverse fault. (b) Particular of S-C structures within the reverse fault.

a Burgers rheology for the asthenosphere, such that the long-term and short-time scale behaviours were represented by Maxwell and Kelvin-Voigt elements, respectively. They also incorporated a transient creep regime suitable for describing low-strain and short-term deformation (of the order of a few years). A direct extrapolation of this model to the lithosphere can be performed assuming a steadystate viscosity $\eta_{S}=10^{22} \mathrm{~Pa} \mathrm{~s}$, which accounts for the selected value of $\eta_{K}$. This estimate of steady-state viscosity can be justified as follows. The creep equation reads (Karato \& Wu 1993):

$\dot{\varepsilon}=A(\sigma / \mu)^{n}(b / d)^{m} e^{[-(E+P V) / R T]}$,

where $A$ is the pre-exponential factor, $\mu$ is the shear modulus, $b$ is the magnitude of the Burgers vector, $d$ is the grain size, $n$ is the stress exponent, $m$ is the grain size exponent, $E$ is the activation energy, $V$ is the activation volume, $P$ is the pressure, and $R$ is the gas constant. A list of values for these parameters can be found in Table 2. Assuming $n=1$ (linear rheology) and solving for the steady-state viscosity gives:

$\eta_{S}=\left(2 A b^{m} / \mu\right)^{-1} d^{m} e^{(E+P V) / R T}$.

We consider a grain size range between $0.1 \mathrm{~mm}$ and $1 \mathrm{~cm}$ according to common estimates for the upper mantle (Hirth \& Kohlstedt 2003; Faul \& Jackson 2005). In general, very small grain sizes are representative of a linear mantle rheology. According to eq. (6), for temperature conditions between 1000 and $1200 \mathrm{~K}$ and pressures of
$1 \mathrm{GPa}$, typical of the subcrustal mantle, the steady-state dry olivine viscosity results to be $\eta_{S} \geq 10^{22} \mathrm{~Pa}$ for any grain size $d \geq 0.1 \mathrm{~mm}$ (except at the highest temperatures for $d=0.1 \mathrm{~mm}$ ). Similarly, the steady-state viscosity of wet olivine is $\eta_{S} \geq 10^{22} \mathrm{~Pa}$ s for any grain size $d \geq 1 \mathrm{~mm}$ (again except at the largest temperatures in the considered interval). Given the uncertainties in grain size, we take $\eta_{S}=10^{22} \mathrm{Pas}$ as a representative value for the lithospheric mantle independently from its volatile content.

Non-linear steady-state viscosities are of the same order of magnitude, using the parameters of Table 2 for typical strain rates of $10^{-15} \mathrm{~s}^{-1}$. These results are in agreement with the estimated range of steady-state viscosities for the lithosphere (Funiciello et al. 2008; Di Giuseppe et al. 2009). In particular, these studies show that the viscosity of the lithosphere should be 100-200 times the viscosity of the asthenosphere, which is in the range $10^{19}-10^{21} \mathrm{Pas}$. Therefore, assuming an average viscosity $\eta=10^{20} \mathrm{~Pa}$ s for the asthenosphere we obtain again $\eta_{S}=10^{22} \mathrm{~Pa}$ for the lithosphere. Regarding the anelastic relaxation modulus, $Y_{K}$, it can be estimated as follows.

Reducing the equations proposed by Faul \& Jackson (2005) for the Burgers rheology to the more simple Kelvin-Voigt model, the time-dependent compliance to the application at time $t=0$ of a unit step of stress is given by the following shear creep function:

$J(t)=J_{0}\left[1+\Delta\left(1-e^{-t / \tau}\right)\right]$, 

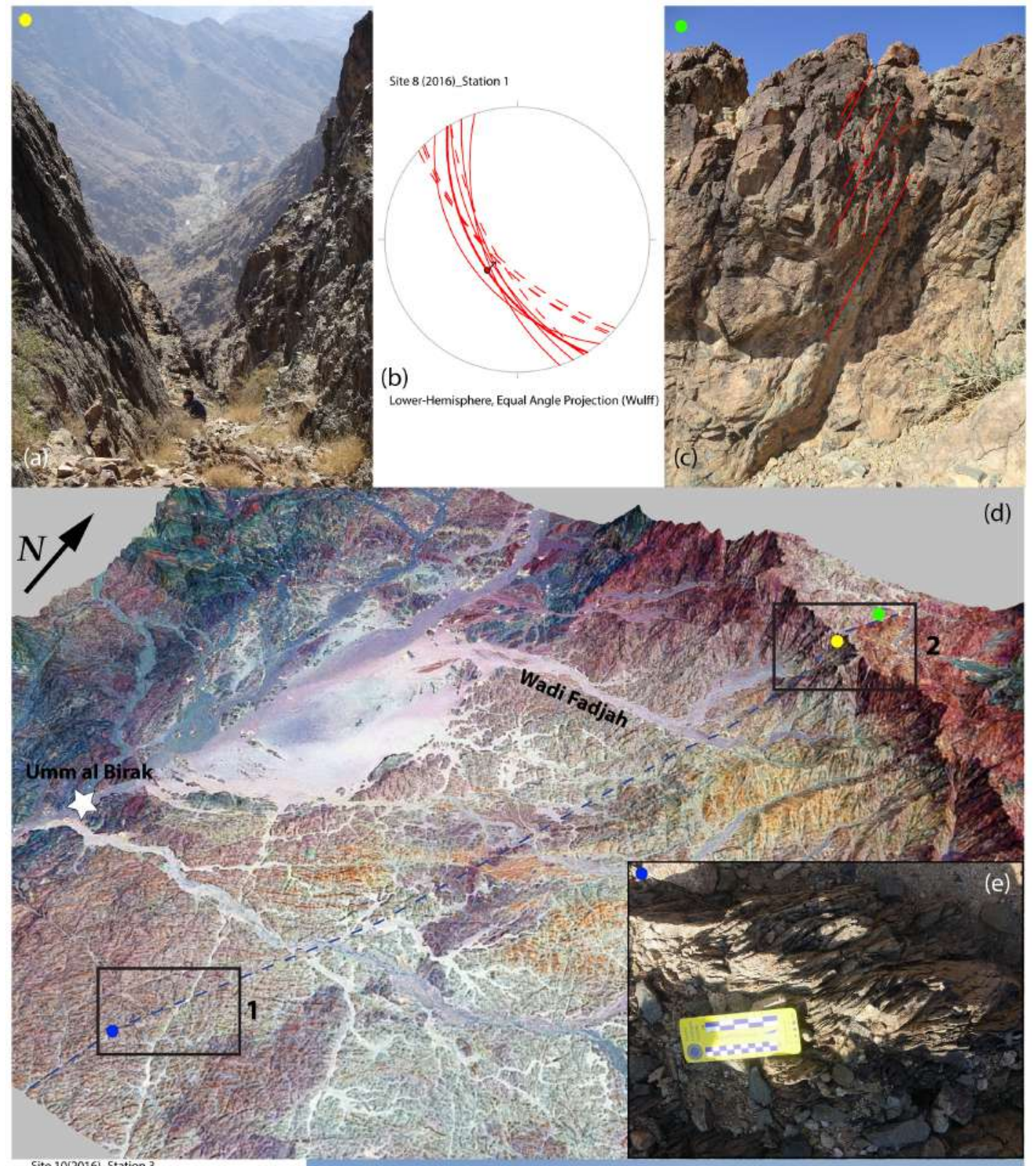

(b)

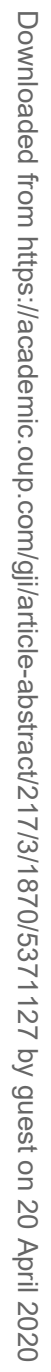
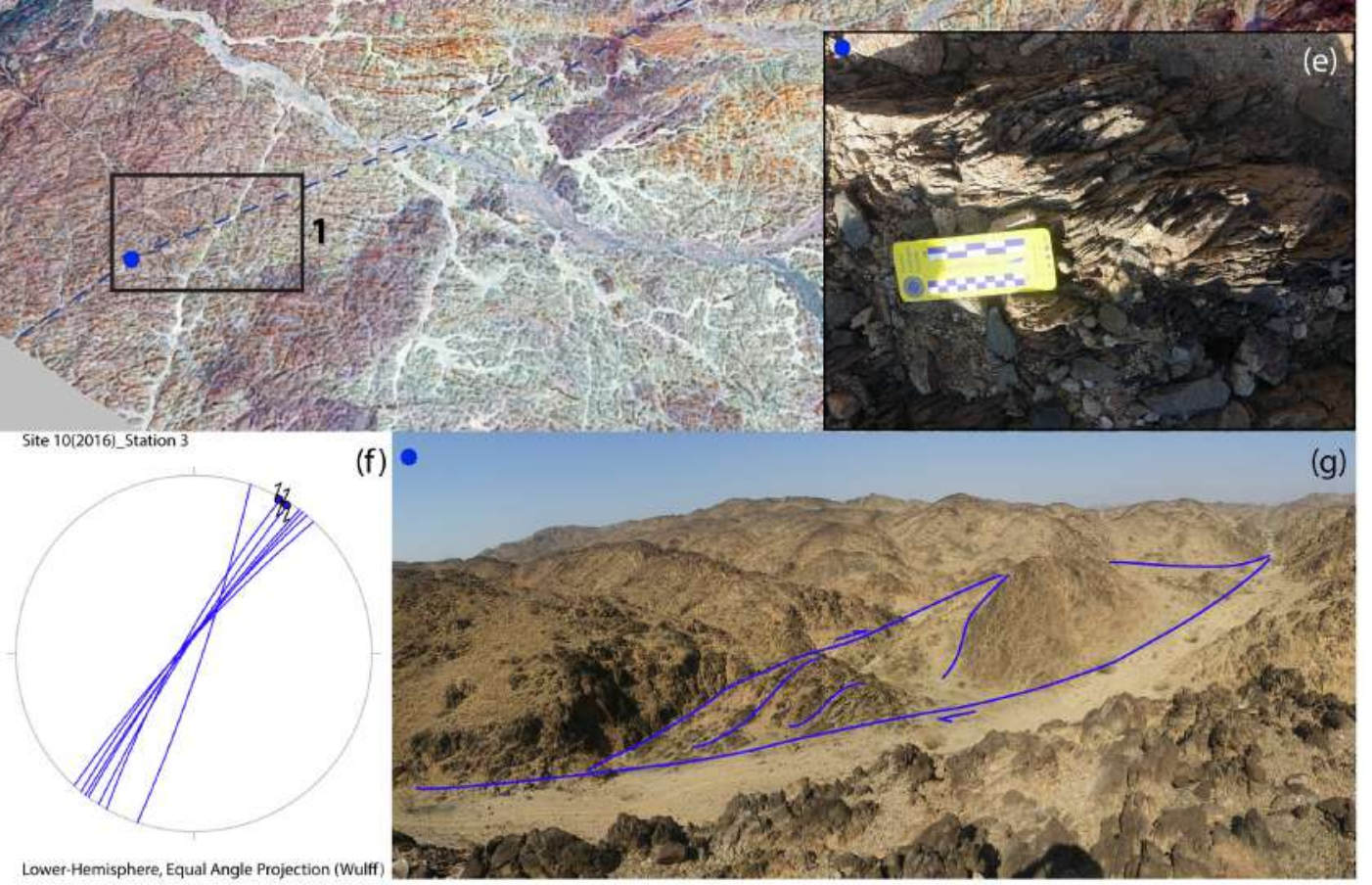

Figure 11. (a) Morphological evidence of the strike-slip fault, which is visible also on the ridge in the picture background. (b) Stereographic projection of the $\mathrm{S}-\mathrm{C}$ structures related to the reverse fault $(\mathrm{S}=$ solid lines; $\mathrm{C}=$ dashed lines). (c) Particular of the $\mathrm{S}-\mathrm{C}$ structure related to the reverse fault. (d) Landsat image of the dextral strike-slip fault at site S4 of Fig. 2. (e) Close-up on the S-C structures related to the strike-slip fault. (f) Stereographic projection of the structures related to the dextral strike-slip (blue lines = fault planes; blue dots = fault striae). (g) Dextral transpressive push-up structures along the dextral strike fault. 
Table 2. Dry and wet olivine parameters for linear and non-linear steadystate rheology. Parameters from Karato \& Wu (1993); for the stress exponent $n$ see Section 5 .

\begin{tabular}{lcc}
\hline Creep mechanism & Dry & Wet \\
\hline Diffusion & $8.7 \times 10^{15}$ & $5.3 \times 10^{15}$ \\
$A\left(\mathrm{~s}^{-1}\right)$ & 1.0 & 1.0 \\
$n$ & 2.5 & 2.5 \\
$m$ & 300 & 240 \\
$E\left(\mathrm{~kJ} \mathrm{~mol}^{-1}\right)$ & 6 & 5 \\
$V\left(\mathrm{~cm}^{3} \mathrm{~mol}^{-1}\right)$ & 80 & 80 \\
$\mu_{0}(\mathrm{GPa})$ & $0.5 \times 10^{-9}$ & $0.5 \times 10^{-9}$ \\
$b(\mathrm{~m})$ & $3.5 \times 10^{22}$ & $2.0 \times 10^{18}$ \\
Dislocation & 3.0 & 3.0 \\
$A\left(\mathrm{~s}^{-1}\right)$ & 0 & 0 \\
$n$ & 540 & 430 \\
$m$ & 15 to 25 & 10 to 20 \\
$\left.E(\mathrm{~kJ} \mathrm{~mol})^{-1}\right)$ & 80 & 80 \\
$V\left(\mathrm{~cm}^{3} \mathrm{~mol}^{-1}\right)$ & $0.5 \times 10^{-9}$ & $0.5 \times 10^{-9}$ \\
$\mu_{0}(\mathrm{GPa})$ & & \\
$b(\mathrm{~m})$ & &
\end{tabular}

where the unrelaxed compliance, $J_{0}$, is given by the reciprocal of the unrelaxed (elastic) shear modulus $Y_{0}$ and $\Delta$ is the anelastic relaxation strength: $\Delta=\left(Y_{0}-Y_{K}\right) / Y_{K}, Y_{K}$ being the relaxed modulus. These authors estimated a value $\Delta=1.4$ for melt-free polycrystalline aggregates of olivine, and an unrelaxed compliance $J_{0}=0.0149 \pm 0.0001 \mathrm{GPa}^{-1}$. Consequently, we obtain for the unrelaxed and relaxed shear moduli a value of $Y_{0}=67 \mathrm{GPa}$ and $Y_{K}=Y_{0} / 2.4=28 \mathrm{GPa}$, respectively. However, Karato \& Wu (1993) proposed a higher value for $Y_{0}$, namely $Y_{0}=80 \mathrm{GPa}$. In this instance, the relaxed modulus would be given by $Y_{K} \cong 33 \mathrm{GPa}$.

\subsection{Non-linear Kelvin rheology}

A non-linear Kelvin-Voigt rheology can be described by a constitutive equation that includes an elastic element and a non-linear Kelvin element:

$\sigma=Y_{K} \varepsilon+\left(\eta_{t}^{*} \dot{\varepsilon}\right)^{1 / n}$,

where $\eta_{t}^{*}=A_{0}^{-1} \exp (H / R T)$ is a non-linear parameter having units $\mathrm{Pa}^{\mathrm{n}} \mathrm{s}$ that will be denoted as pseudo-viscosity, while $A_{0}, n$ (stress exponent), and $H=E+P V$ are transient creep parameters. Eq. (8) can be easily solved under constant stress conditions, $\sigma(t)=\sigma_{0}$, by separation of variables:

$\int \frac{\mathrm{d} \varepsilon}{\left[\sigma_{0}-Y_{K} \varepsilon\right]^{n}}=\frac{t}{\eta_{t}^{*}}+C$,

where $C$ is a constant. In the loading phase, we set $\varepsilon(0)=0$, while the creep curve after unloading is determined setting $\sigma_{0}=0$ and assuming an initial strain $\varepsilon(0)=\varepsilon_{0}$. Therefore, for $n \neq 1$ the loading and unloading curves are given, respectively, by

$\varepsilon(t)=\frac{1}{Y_{K}}\left\{\sigma_{0}-\left[\sigma_{0}^{1-n}-\frac{(1-n) Y_{K}}{\eta_{t}^{*}} t\right]^{1 /(1-n)}\right\} ; n \neq 1$

$\varepsilon(t)=\left[\frac{(1-n)\left(-Y_{K}\right)^{n}}{\eta_{t}^{*}} t+\varepsilon_{0}^{1-n}\right]^{1 /(1-n)} ; n \neq 1$.

Solution (11) requires that the stress exponent $n$ be a positive odd integer. In this instance, the anelastic relaxation strain and strain rate functions assume the form

$\varepsilon(t)=\left[-\frac{(1-n) Y_{K}^{n}}{\eta_{t}^{*}} t+\varepsilon_{0}^{1-n}\right]^{1 /(1-n)} ; n \neq 1$, odd integer

$\dot{\varepsilon}(t)=-\frac{1}{\eta_{t}^{*}}\left[Y_{K} \varepsilon(t)\right]^{n} ; n \neq 1$, odd integer.

To estimate the non-linear transient pseudo-viscosity, $\eta_{t}^{*}$, we can assume that:

1. Both the transient and steady-state non-linear creep are described by a power law with a unique odd integer stress exponent $n$, although the other parameters could be different (Freed et al. 2012):

$\dot{\varepsilon}=A(\sigma / \mu)^{n} e^{-H / R T}$,

where $H$ is the activation enthalpy $(H=E+P V)$. In this instance, by eq. (14) the two viscosities can be expressed directly in terms of pseudo-viscosities:

$\eta_{s}=\left(\eta_{s}^{*}\right)^{1 / n} \dot{\varepsilon}^{(1-n) / n}$

$\eta_{t}=\left(\eta_{t}^{*}\right)^{1 / n} \dot{\varepsilon}^{(1-n) / n}$.

We can determine the steady-state pseudo-viscosity, $\eta_{s}^{*}$, using the parameters of Karato \& Wu (1993) for $T=1000 \mathrm{~K}$ and $P=1 \mathrm{GPa}$, obtaining: $\eta_{s}^{*}=7.65 \times 10^{44} \mathrm{~Pa}^{\mathrm{n}} \mathrm{s}$ for dry olivine and $\eta_{s}^{*}=4.62 \times 10^{37} \mathrm{~Pa}^{\mathrm{n}} \mathrm{s}$ for wet olivine.

2 . The relation between the anelastic viscosity, $\eta_{t}$, and the steadystate viscosity, $\eta_{s}$, can be described by a linear expression of the form:

$\eta_{t}=\gamma \eta_{s}$

where $\gamma \leq 1$ is a constant. Substituting this expression in eqs (15) and (16) gives

$\eta_{t}^{*}=\gamma^{n} \eta_{s}^{*}$.

A relation between the transient and steady-state viscosity as given in eq. (17) can be empirically justified by three sets of observations: (1) the dependence of the seismic attenuation (quality factor $Q$ ) and anelastic creep on similar microphysical processes (Faul \& Jackson 2015); (2) the experimentally determined relation between $Q$ and the steady-state viscosity in peridotite (Sato 1991); and (3) the empirical relation between the transient and steady-state viscosity derived from post-seismic deformation (Pollitz 2003, 2005 and additional references mentioned in Section 5.1).

We assume that $n=3$ for both the wet and dry conditions. A value $n=3$ for the wet rheology coincides with that proposed by Karato \& Wu (1993), but the exponent used by these authors for the dry conditions $(n=3.5)$ is not compatible with the solution (eq. 12). However, Freed et al. (2006) found that a power-law exponent $n=3.5 \pm 0.5$ for the upper mantle, combined with a power-law exponent $n=3 \pm 1$ in the lower crust, provided the best fit of theoretical displacements to observed surface velocities. The value of the parameter $\gamma$ is not known a priori, so we test four different possibilities in the range $0-1$ : the two end members $\gamma=1$ and $\gamma=0.01$ and the intermediate values $\gamma=0.5$ and $\gamma=0.1$.

A characterization of the time evolution of the strain and strain rate during anelastic relaxation, both in the linear and non-linear cases, can be accomplished introducing three characteristic times: (1) the relaxation time constant $\tau$, which is the time required for the initial strain $\varepsilon_{0}$ to decrease by a factor $e^{-1}$ in the linear case; (2) the 
time $t_{1}$ required for the initial strain to decrease by a factor 10 (i.e. such that $\left.\varepsilon\left(t_{1}\right)=0.1 \varepsilon_{0}\right)$; and (3) the time, $t_{2}$, required for the initial strain rate to be reduced to a value between $10^{-16}$ and $10^{-18} \mathrm{~s}^{-1}$ (which is a range of typical 'background' values for the strain rate in stable tectonic plate interiors and passive continental margins).

The results for the linear and non-linear cases are shown in Table 3. For given parameters, the non-linear strain rate decreases more rapidly than the linear strain rate in the initial stages of relaxation, but takes a longer time to reach the background strain rate. In the present context, the most relevant characteristic time is the duration of the transient phase, that is the time $t_{2}$ it takes for the strain rate to fall to the steady-state background value. A plot of the time evolution of strain rates is shown in Fig. 12. In the case of linear viscosity, assuming $Y_{K}=30 \mathrm{GPa}$, the rheology implies very short characteristic times and therefore does not predict a time evolution compatible with the geological and magnetic observations. The non-linear wet rheology implies very short characteristic times $t_{2}$ for any value of $\gamma$ except when approaching unity, while in the case of dry olivine $t_{2}$ falls in the right range for low values of $\gamma$ (4.8 Myr for $\gamma=0.01$ if the background strain rate is taken as $10^{-18} \mathrm{~s}^{-1} ;<11 \mathrm{Myr}$ for $\gamma<0.5$ and a background strain rate of $\left.10^{-16} \mathrm{~s}^{-1}\right)$. The latter finding is in accordance with the observations discussed in Section 4, which suggest that the transient viscosity is one to two orders of magnitude less than the steady-state viscosity. For instance, for a dry non-linear rheology with $\gamma=0.1$ and assuming a background strain rate of $10^{-16} \mathrm{~s}^{-1}$ we obtain a very reasonable value $t_{2} \cong 2.24 \mathrm{Myr}$ and a realistic value for the initial strain rate: $|\dot{\varepsilon}(0)|=3.53 \times 10^{-11} \mathrm{~s}^{-1}$. Therefore, dry transient rheology with viscosity one to two orders of magnitude less than steady-state viscosity provides results that are compatible with the geological and geophysical observations. Conversely, although wet olivine can display characteristic times $t_{2}$ of the same order of magnitude as the observations $\left(t_{2} \cong 1.9 \mathrm{Myr}\right.$ and $t_{2} \cong 0.9 \mathrm{Myr}$ assuming a background strain rate of $10^{-18} \mathrm{~s}^{-1}$ and $\gamma=1$ and $\gamma=0.5$, respectively), it would result in ultrahigh initial strain rates difficult to reconcile with observations $\left(5.84 \times 10^{-7} \mathrm{~s}^{-1}\right.$ and $4.86 \times 10^{-6}$ $\mathrm{s}^{-1}$ for $\gamma=1$ and $\gamma=0.5$ ).

\section{NUMERICAL TEST}

To test the hypothesis that the lithosphere can retain and accumulate elastic energy during the rifting stage, we performed a 2-D numerical experiment using the finite element code Underworld II (Moresi et al. 2003, 2007), starting from a set of models that had been created to study the effect of edge-driven mantle convection on the rifting process (Fierro 2018). In this experiment, we assumed a viscoelastic lithosphere of constant thickness, except for a central thinned region (e.g. after thermal erosion), whose mechanical behaviour is governed by a Burgers rheology (Fig. 3) without instantaneous elasticity (i.e. by a standard fluid model). The model domain extended to the whole upper mantle with an aspect ratio of 4. The boundary conditions for the velocity field were assigned as follows (Fig. 13): (1) At the western edge, $v_{x}=v_{y}=0$; (2) at the lower boundary $\left(H=660 \mathrm{~km}\right.$ discontinuity), $v_{x}=v_{y}=0$; (3) at the upper boundary, $v_{y}=0$ (free slip); (4) at the eastern boundary, $v_{x}(z)=v_{0}$ for $z \leq z_{\mathrm{LAB}}\left(v_{0}=15 \mathrm{~mm} \mathrm{yr}^{-1}\right.$ being the far-field plate velocity, $z=660-y$, LAB $=$ lithosphere-asthenosphere boundary), a Couette flow between the $\mathrm{LAB}$ and $300 \mathrm{~km}$ depth, and a Poiseuille counterflow between 300 and $410 \mathrm{~km}$ depth, in agreement with the upper mantle circulation model illustrated in Schettino (2014). The parameters of the lower asthenosphere counterflow were determined in such a way that the total mass of the domain is conserved. In this instance, the flux through the walls of the domain $\mathbf{D}$ is always zero:

$\Phi=\oint_{\mathbf{D}} \rho \mathbf{v} \cdot d \boldsymbol{S}=0$,

where $\rho$ is the density. In this experiment, we focused on the evolution of the lithosphere, and thereby the description of the asthenosphere and transition zone dynamics was maintained as simple as possible. For example, we assumed no adiabatic gradient in the initial conditions of temperature below the LAB and a constant viscosity $\eta_{T}=10^{23} \mathrm{Pas}$ in the transition zone. The rheology of the asthenosphere was described by a power-law dry olivine dislocation creep with parameters listed in Table 2 and exponent $n=3.5$ (Karato \& Wu 1993). The effective viscosity of the lithosphere was calculated as follows. For a standard fluid, the total strain is the sum of a transient strain associated with the Kelvin-Voigt element, $\varepsilon_{K}$, and the steady strain $\varepsilon_{S}$. Therefore, assuming that stress changes at a much lower rate than strain, we can use the loading phase solution (10) for constant stress at each time step of the numerical simulation. In this instance, we have

$\dot{\varepsilon}(t)-\dot{\varepsilon}_{S}(t)=\frac{1}{\gamma^{n} \eta_{S}^{*}}\left[\sigma^{1-n}-\frac{(1-n) Y_{K}}{\gamma^{n} \eta_{S}^{*}} t\right]^{\frac{n}{1-n}}$,

where we have used eq. (10). Solving for the stress gives

$\sigma=\left\{\frac{(1-n) Y_{K}}{\gamma^{n} \eta_{S}^{*}} t+\gamma^{1-n}\left[\eta_{S}^{*}\left(\dot{\varepsilon}-\dot{\varepsilon}_{S}\right)\right]^{\frac{1-n}{n}}\right\}^{\frac{1}{1-n}}$.

Consequently, the effective viscosity $\eta=\sigma / 2 \dot{\varepsilon}$ will be given by

$\eta=\frac{1}{2 \dot{\varepsilon}}\left\{\frac{(1-n) Y_{K}}{\gamma^{n} \eta_{S}^{*}} t+\gamma^{1-n}\left[\eta_{S}^{*}\left(\dot{\varepsilon}-\dot{\varepsilon}_{S}\right)\right]^{\frac{1-n}{n}}\right\}^{\frac{1}{1-n}}$.

This is the viscosity used in the numerical solution of NavierStokes equations by the Underworld 2 code. In eq. (22), we used $n=3$ and $\gamma=0.1$, in agreement with the results discussed in the previous section. Regarding the steady-state strain rate, we assumed a constant background strain rate $\dot{\varepsilon}_{S}=10^{-18}$. Computer animations showing the evolution of temperature, viscosity, second invariant of the strain rate, second invariant of the stress, components of the deviatoric stress, components of the velocity field, and velocity at the Earth's surface are available as supplementary material. A comparison of temperature and velocity fields at the initial time $t=0 \mathrm{Myr}$ with the corresponding fields after $15 \mathrm{Myr}$ is shown in Fig. 14. This plot shows that the whole lithosphere effectively experiences thermal thinning under far-field extensional forces with the assumed parameters, so thermal diffusion in the lithosphere does not prevail on the heat advection mechanism (e.g. Salerno et al. 2016). It also shows an increase of mantle upwelling with time below the weak axial zone and a widening of the central hyperextended region. The evolution of the effective viscosity is illustrated in Supplementary Fig. S1. We note that a central low-viscosity zone in the lithosphere progressively localizes in the axial region. The distribution of strain rates at the initial time and after 15 Myr (Supplementary Fig. S2) also shows the presence of higher strain rate zones in the axial region of the lithosphere, in the asthenosphere below the rift axis, and along the LAB. Plots of the stress second invariant and the components of the stress deviator are illustrated in Figs 15-18. In particular, Fig. 15 shows that stress is always concentrated in the widening axial zone of the lithosphere, but it increases progressively. The evolution of the velocity field can be better understood through an analysis of its components $v_{x}$ and $v_{y}$ (Figs 19 and 20). Fig. 19 shows that the horizontal component of velocity 
Table 3. Characteristic times for dry and wet olivine in the linear and non-linear Kelvin-Voigt rheology.

\begin{tabular}{|c|c|c|c|c|c|c|}
\hline & \multicolumn{3}{|c|}{ Dry } & \multicolumn{3}{|c|}{ Wet } \\
\hline Linear* & $1.06 \times 10^{-3}$ & $2.40 \times 10^{-3}$ & $1.82 \times 10^{-2}$ & $1.06 \times 10^{-3}$ & $2.40 \times 10^{-3}$ & $1.82 \times 10^{-2}$ \\
\hline Non-linear $(\gamma=0.5)$ & 0.36 & 5.51 & 241.69 & $<5 \times 10^{-5}$ & $<0.01$ & 0.94 \\
\hline Non-linear $(\gamma=0.1)$ & $2.85 \times 10^{-3}$ & 0.04 & 48.35 & $<5 \times 10^{-5}$ & $<0.01$ & 0.19 \\
\hline Non-linear $(\gamma=0.01)$ & $<5 \times 10^{-5}$ & $<0.01$ & 4.83 & $<5 \times 10^{-5}$ & $<0.01$ & 0.02 \\
\hline
\end{tabular}

*Steady-state viscosity assumed the same for both cases (see Section 4.1).

in the lithosphere increases rapidly in the axial zone and that the velocity gradient increases with time in this region. We also note in Fig. 20 that a widening zone of upwelling exists below the axial region of the rift and that the vertical component of the velocity increases progressively. Such a proto-melting regime could induce partial melting even during the rifting phase. In this instance, we would have underplating of basaltic melts with a MORB signature, with production of gabbros at progressively shallower depths during rifting as described by Ligi et al. (2018). Finally, the evolution of the velocity field at the Earth's surface, $v_{x}(x, 0, t)$, is illustrated in Fig. 21 at 5 -Myr time steps. We note that plate velocities decrease with time along the western side of the rift, while they increase along the eastern side. The horizontal gradient of velocity decreases with time everywhere except in the axial region, where it increases.

\section{DISCUSSION}

The main objective of this paper was to provide a rheological explanation for some enigmatic geological and geophysical observations of the rift-drift transition phase in the Red Sea region. It does not attempt to explain either the whole range of phenomena that occur after the break-up of continents or the physics of this process in general. Consequently, the following discussion will be focused on the proposed rheological model of rift-drift transition, although it is important to highlight some points. The observation of recent strike-slip motion along both main transverse structures and secondary NE-SW-oriented faults of the Red Sea margin, sometimes with evidence of right-lateral overprint on previous syn-rift leftlateral kinematics and often accompanied by reverse components, cannot be explained in terms of isostatic post-rift adjustments, thermal relaxation, or dynamic topography. The important horizontal component of deformation, which is accompanied by strong magnetic anomalies and sometimes by a modern pattern of seismicity, prevents such a class of interpretations. In addition, the observed tectonic inversion of rift structures, which is very similar to the inversion that occurred along the eastern North American margin at the onset of seafloor spreading in the central Atlantic (Withjack et al. 1995; Schlische et al. 2003), requires in any case a significant horizontal component of compressional stress, in agreement with the mechanism of anelastic relaxation described above.

The results presented in the previous sections show that nonlinear anelastic relaxation is a valid working hypothesis to account for the initial fast pulse of seafloor spreading and the geological evolution of passive margins. In recent studies (e.g. Lucazeau et al. 2008; Ligi et al. 2011, 2012; Korostelev et al. 2015, 2016), it has been suggested that a rapid active pulse of seafloor spreading at the rift-drift transition is a consequence of fast mantle upwelling associated with edge-driven convection (King \& Anderson 1998). In this instance, the increased velocity of asthenosphere upwelling would be determined by the positive feedback of small-scale convective cells that form when the rising of hot melt-rich low-viscosity mantle material produces a sharp horizontal thermal gradient with respect to the nearby cold continental lithosphere. Although this model is attractive, and there is little doubt that small-scale convection plays an important role before and after the onset of seafloor spreading (van Wijk at al. 2008), it can hardly explain the inversion of extensional structures along the extended continental margins, the formation of new compressional features such as anticlines and the apparent landward migration of these structures. In fact, the traction $\boldsymbol{\tau}_{B}(\mathbf{x})$ exerted at a basal point $\mathbf{x}$ of a lithospheric plate, associated with boundary torques (e.g. slab pull), is related to the steady equilibrium velocity, $\mathbf{v}_{0}$, at which the plate is moving relative to the top transition zone by the equation:

$\boldsymbol{\tau}_{B}(\mathbf{x})=\frac{\eta}{h} \mathbf{v}_{0}(\mathbf{x})+\frac{h}{2} \nabla p$

where $\eta$ and $h$ are the average asthenosphere viscosity and thickness, respectively, and $\nabla p$ is the lateral pressure gradient in the asthenosphere. The first term on the right-hand side of eq. (23) represents a passive viscous drag, while the second term is an active drag exerted at the base of the lithosphere by a pressure-driven asthenosphere flow in the case of lateral changes in the pressure field (cf. e.g. Schettino 2014). Therefore, assuming that the only active drag is associated with a small-scale convection confined beneath the extended plate margins, a differential drag $\delta \boldsymbol{\tau}=\frac{1}{2} h \nabla p$ should exist between continental margins and plate interiors. Taking an asthenosphere channel with thickness $h=300 \mathrm{~km}$ and a strong lateral pressure gradient $\partial p / \partial x=10 \mathrm{kPa} \mathrm{m}^{-1}$ would give $\delta \tau=1.5 \mathrm{MPa}$, which is well below the maximum sustainable differential stress at the base of a hot and thinned continental lithosphere (e.g. Ranalli \& Murphy 1987). Consequently, edge-driven convection cannot explain basin inversion at the onset of seafloor spreading, while it provides a good physical ground for the uplift of the rift shoulders (Buck 1986). In general, we believe that edge-driven convection and anelastic relaxation both play an important role, respectively before and after the onset of seafloor spreading. Therefore, they should be regarded as complementary processes that mark the transition from continental rifting to seafloor spreading. In particular, the first can explain the uplift of the rift shoulders while the latter provides a driving mechanism for the post-rift phase of fast spreading, compression, and inversion of the rift structures.

It is important to note that the feasibility of anelastic relaxation as a driving mechanism for the post-rift contraction of the continental margins strongly depends on the choice of rheological parameters. Here we have shown that a non-linear Kelvin-Voigt model provides a realistic solution, provided that (1) the stress exponent $n$ is an odd integer, and we have chosen the value $n=3$; (2) the lithosphere is sufficiently dry; and (3) the anelastic viscosity, $\eta_{t}$, is about $1 / 10-1 / 100$ of the steady-state viscosity. With reference to the first point, a large number of laboratory experiments show that the value 


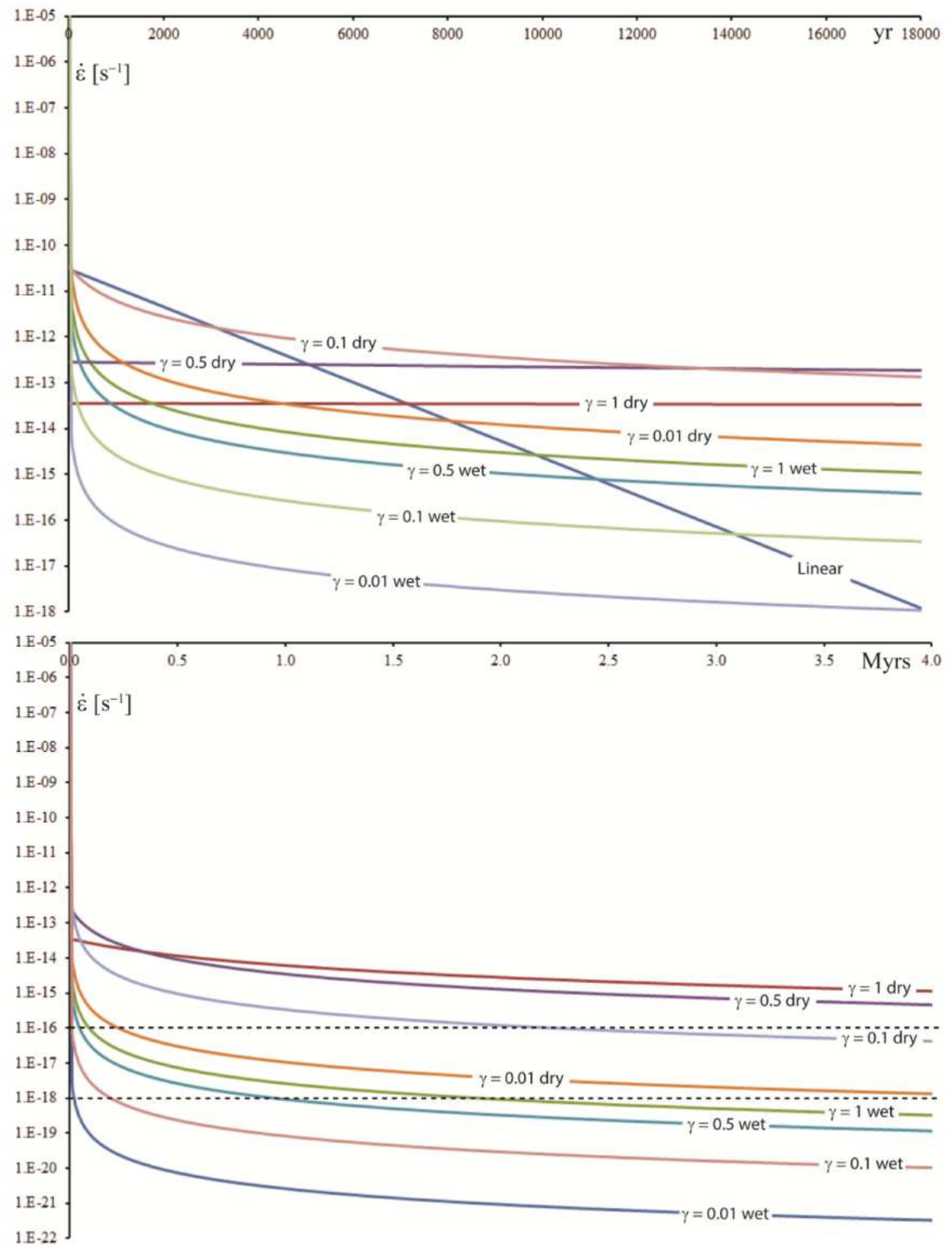

Figure 12. Short-term (upper panel) and long-term (lower panel) strain rates for nine Kelvin-Voigt rheological models. The $10^{-16}$ and $10^{-18}$ dotted lines indicate the range of possible background strain rates for stable passive continental margins.

$n=3$ represents a minimum in the range of possible stress exponents, which is generally considered to be the interval 3-4 for dry olivine (e.g. Ranalli 1995; Fernàndez \& Ranalli 1997 and references therein). However, theoretical arguments show that the power-law equation acquires a simple physical meaning for $n=3$ (Stocker \& Ashby 1973; Evans \& Knowles 1977; Biberger \& Blum 1989) and this value is the most commonly used in geodynamic modelling.
As to the possibility of modelling the post-rift continental margin lithosphere by dry polycrystalline olivine rheology, the following observations are relevant. Although the onset of continental rifting requires some degree of hydration (and associated weakening) of the lithosphere (e.g. Dixon et al. 2004; Li et al. 2008), the process itself implies progressive dehydration due to mantle melting. Nielsen \& Hopper (2004) have shown that lithosphere mantle dehydration is 


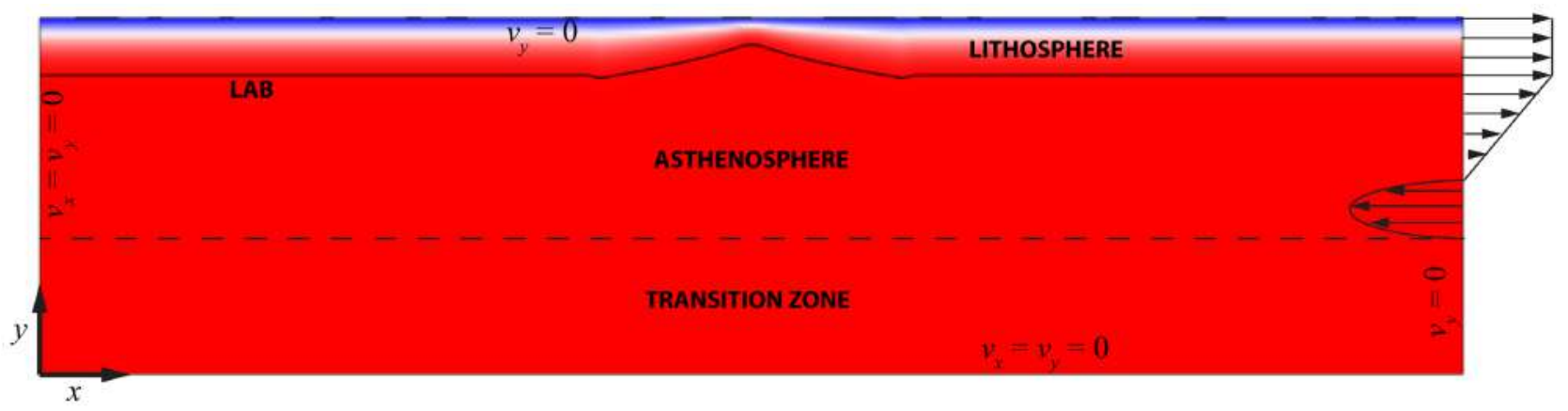

$T[\mathrm{~K}]$

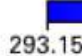

1573.2

Figure 13. Boundary conditions on velocities and initial conditions on temperature in the domain $\mathbf{D}$ for the numerical model of rifting evolution.
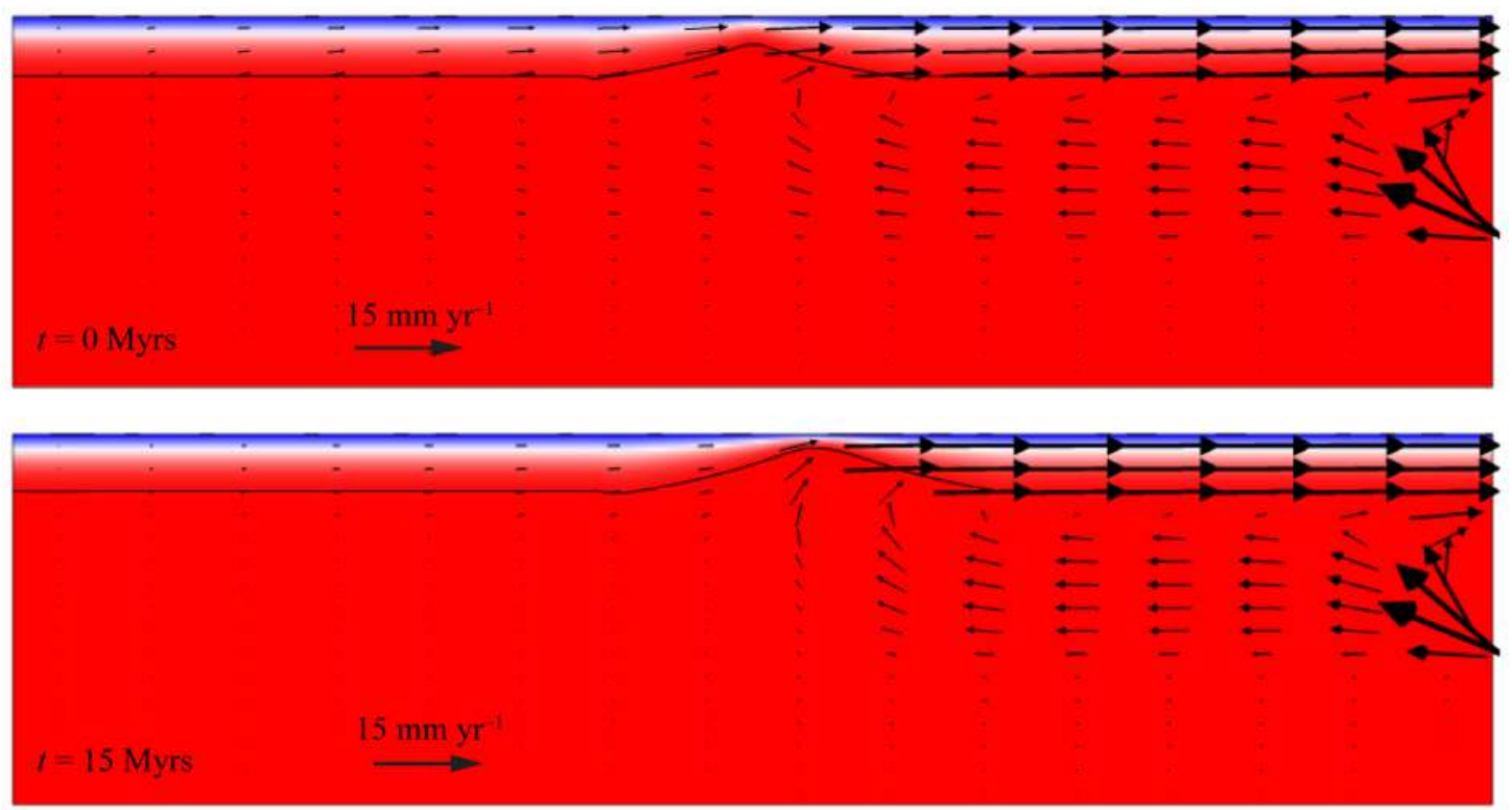

$T[\mathrm{~K}]$

Figure 14. Temperature and velocity fields at $t=0 \mathrm{Myr}$ and after $15 \mathrm{Myr}$.

a dominant process during extension and that after only 2 per cent of melting mantle material is rapidly dehydrated and the viscosity is increased by two orders of magnitude. Therefore, we expect that the lithosphere is close to dry conditions at the end of the rifting process.

Finally, our choice of $10^{-16}$ to $10^{-18} \mathrm{~s}^{-1}$ as the range of background values for the strain rate can be justified as follows. It is generally accepted that $\dot{\varepsilon} \sim 10^{-18} \mathrm{~s}^{-1}$ in stable tectonic plate interiors (Liu \& Zoback 1997 and references therein). In active continental rifts, the extensional strain rate at distance $\zeta$ from the Euler pole and time $t$ is determined by the following law (Schettino et al. 2016), which can be obtained immediately from eq. (1):

$\dot{\varepsilon}(\zeta, t)=\frac{\omega_{0} R \sin (\zeta / R)}{\omega_{0} R \sin (\zeta / R)\left(t-t_{0}\right)-L_{0}}$.
Assuming $L_{0}=500 \mathrm{~km}, \omega_{0}=0.5^{\circ} \mathrm{Myr}^{-1}$ and $\zeta=1000 \mathrm{~km}$, we have $\dot{\varepsilon} \approx 4-5 \times 10^{-16} \mathrm{~s}^{-1}$. In general, application of eq. (20) to rift zones shows that the strain rate is always between $10^{-16}$ and $10^{-15} \mathrm{~s}^{-1}$. Therefore, we consider $\dot{\varepsilon} \sim 10^{-16} \mathrm{~s}^{-1}$ as a lower limit for the extensional strain rate during rifting before the development of true passive continental margins.

Some concluding remarks about the non-linear viscoelastic behaviour of the continental lithosphere during the rifting phase concern two aspects of the results of our numerical experiment, which may contribute to a better understanding of the rift-drift transition. First, we note that the predicted evolution of the velocity field at the Earth's surface during the rifting stage guarantees kinematic continuity to the rift-drift transition. In fact, Fig. 21 shows that plate velocities decrease progressively to the west of the rift axis, while they increase across the eastern side. Virtually, at the onset of 

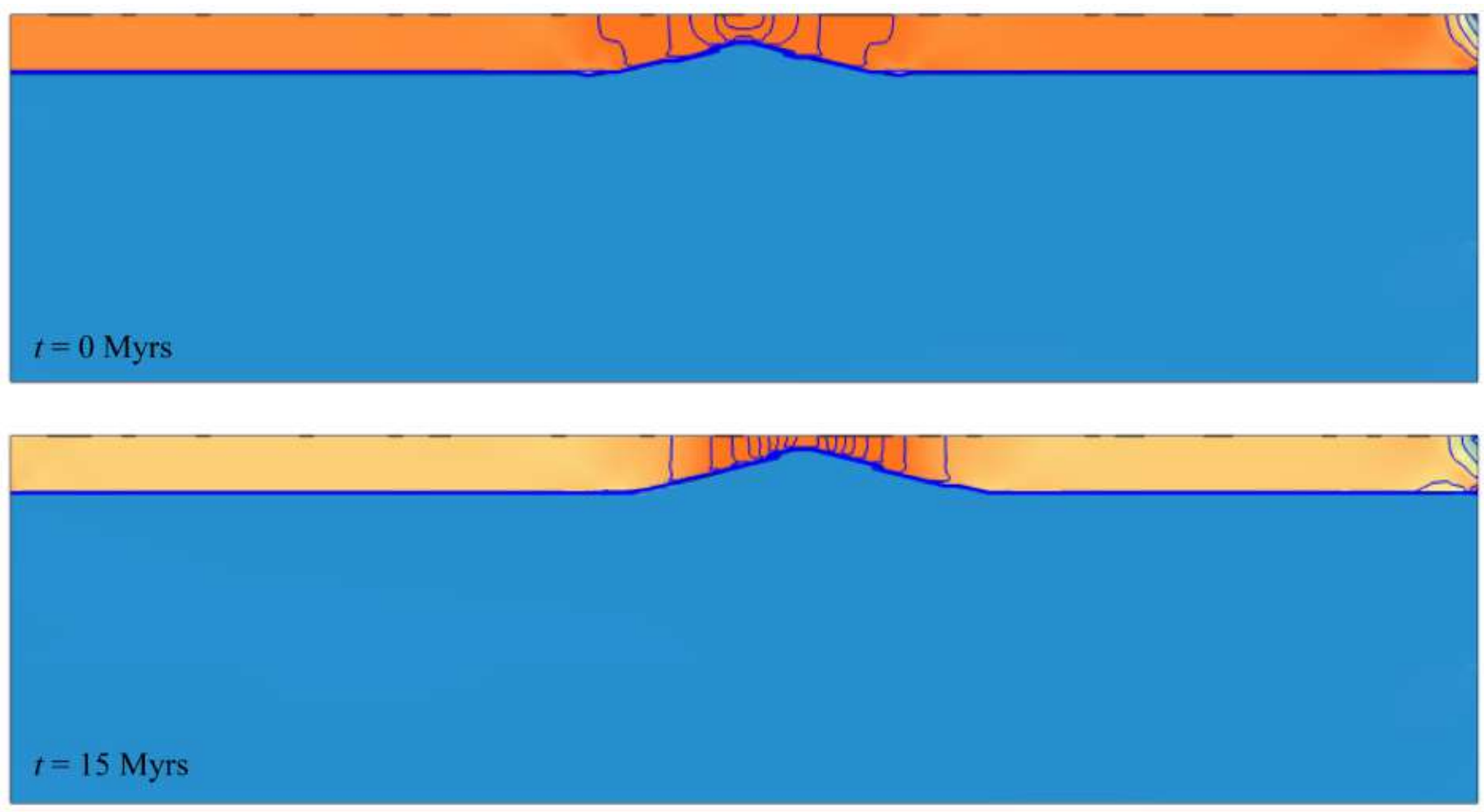

\section{$\sigma[\mathrm{MPa}]$}

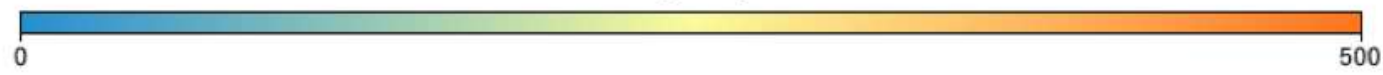

Figure 15. Second invariant of the stress field at $t=0 \mathrm{Myr}$ and after $15 \mathrm{Myr}$. Contour lines are spaced $100 \mathrm{MPa}$.
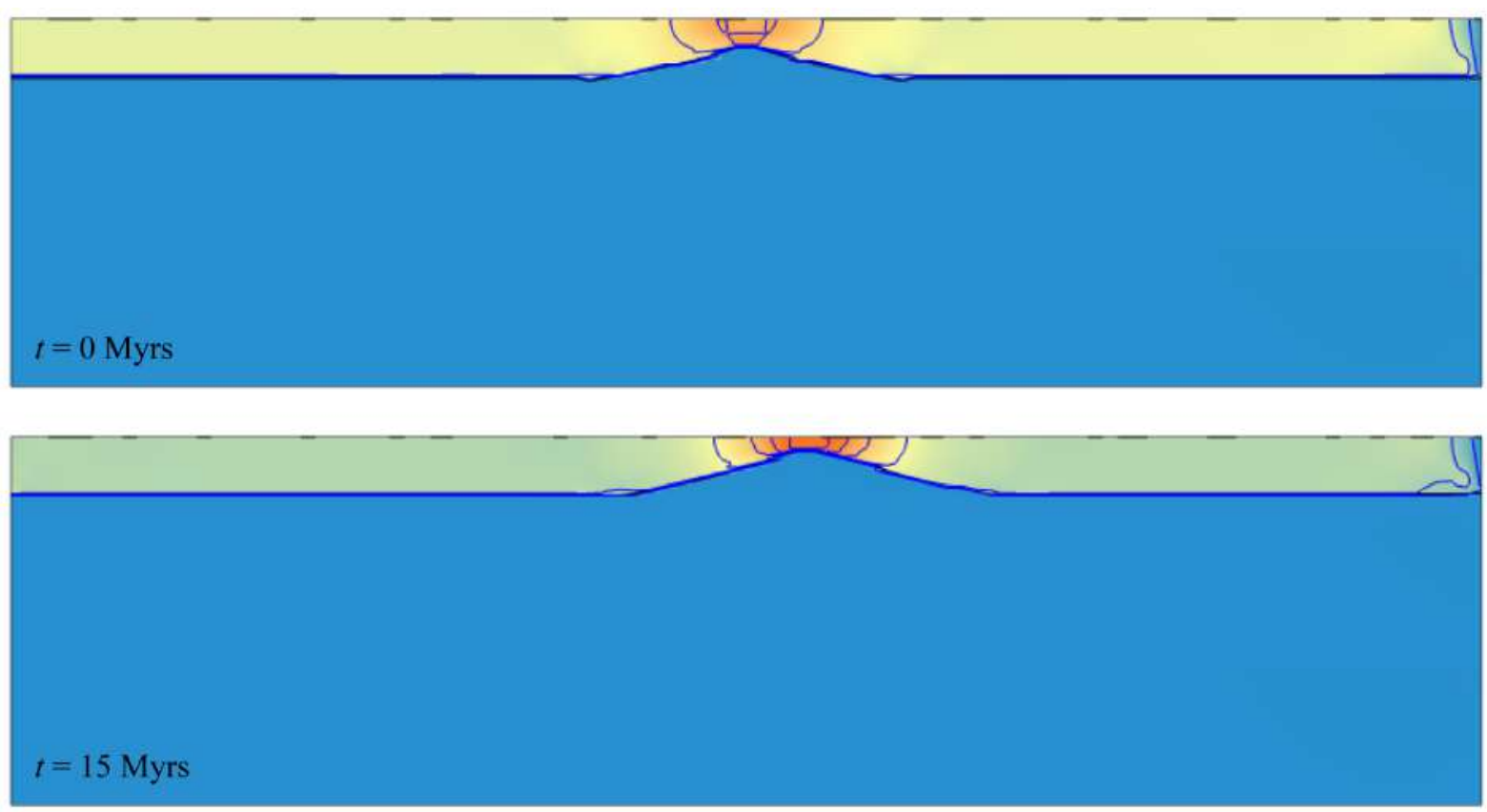

$$
\sigma_{x x}^{\prime}[\mathrm{MPa}]
$$

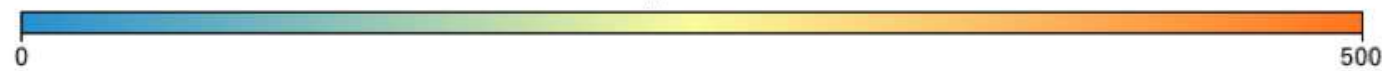

Figure 16. Component $x x$ of the deviatoric stress field at $t=0 \mathrm{Myr}$ and after $15 \mathrm{Myr}$. Contour lines are spaced $100 \mathrm{MPa}$. 

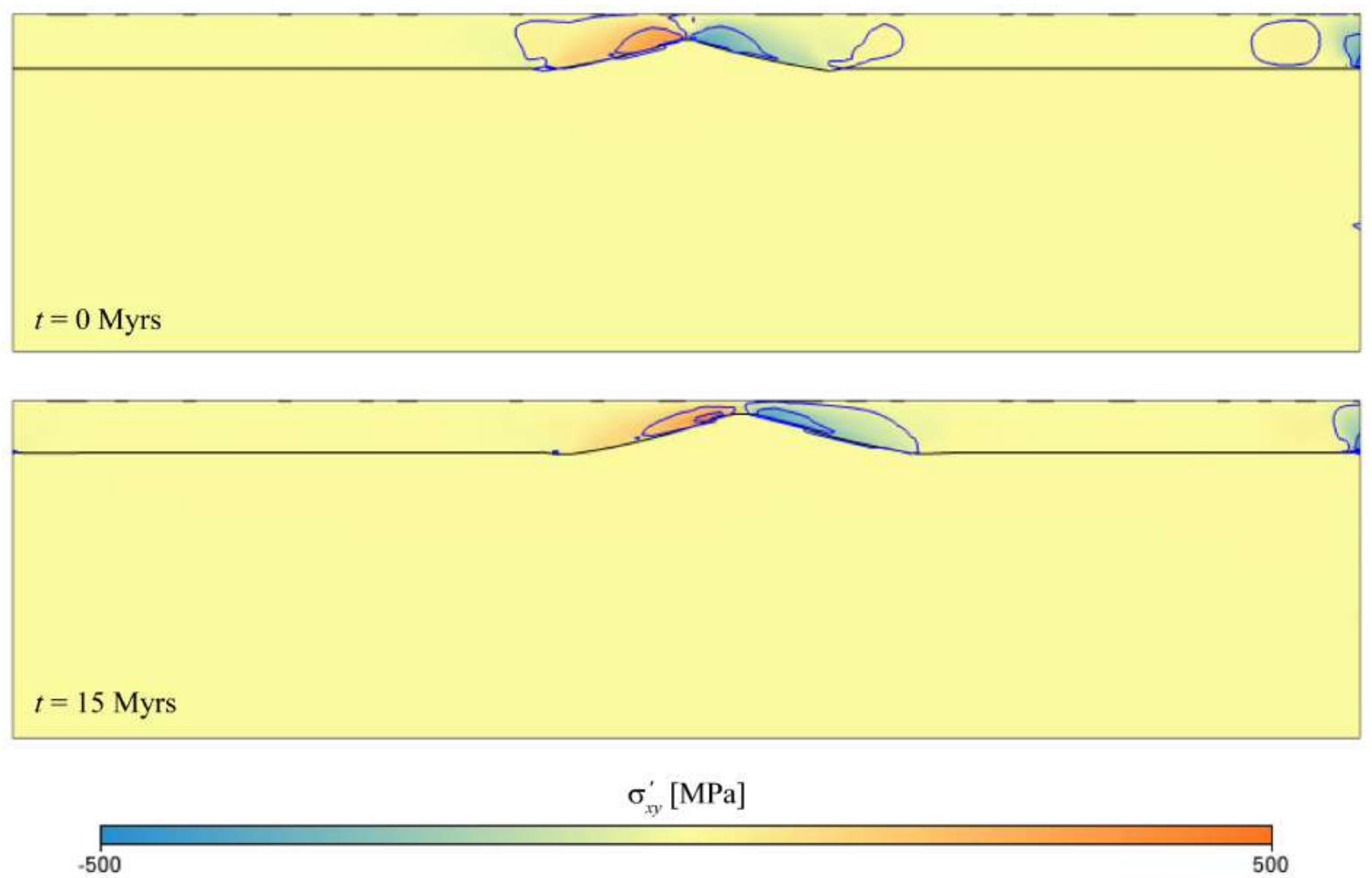

Figure 17. Component $x y$ of the deviatoric stress field at $t=0 \mathrm{Myr}$ and after $15 \mathrm{Myr}$. Contour lines are spaced $100 \mathrm{MPa}$.
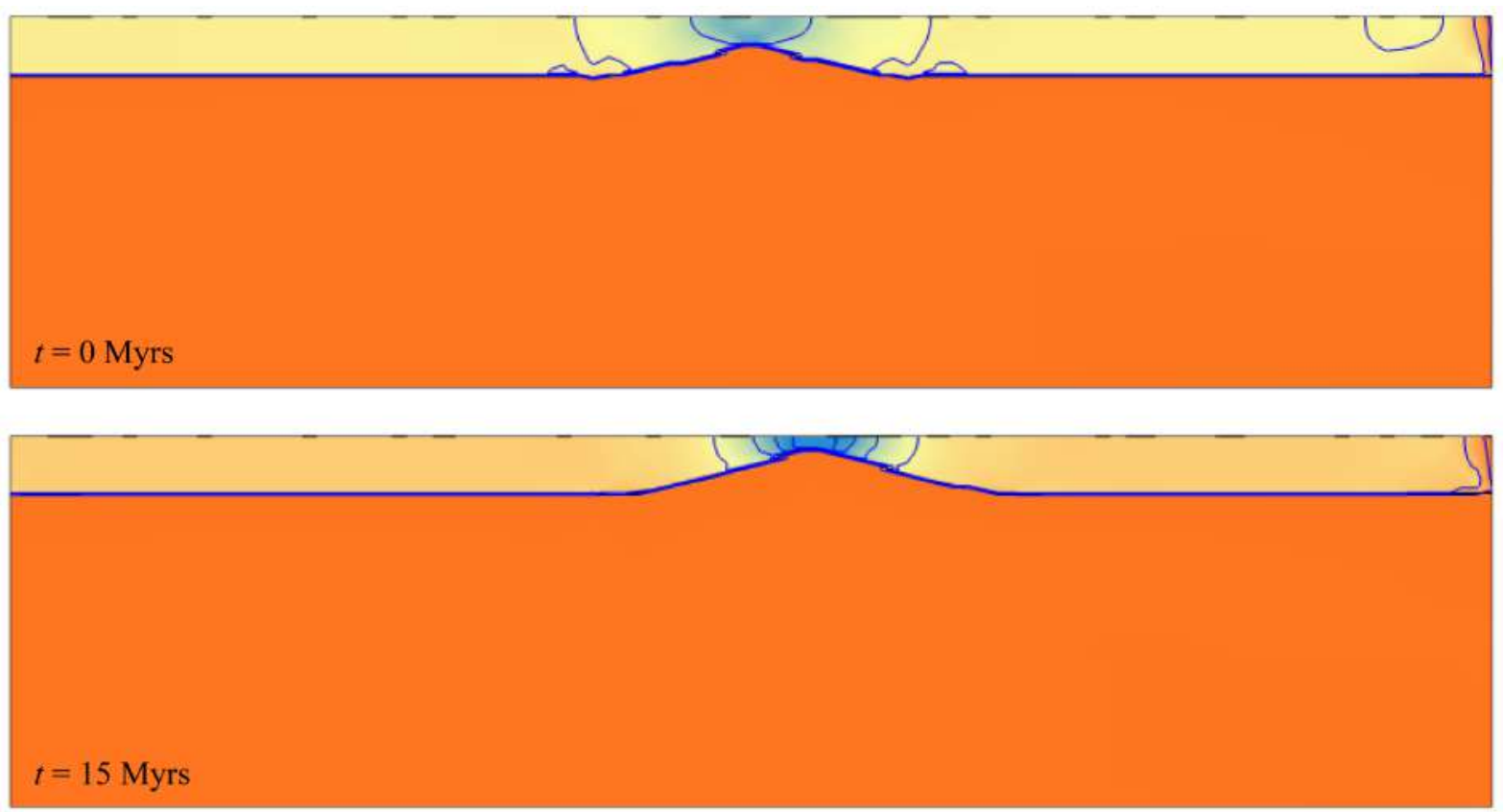

$\sigma_{y y}^{\prime}[\mathrm{MPa}]$

500

Figure 18. Component $y y$ of the deviatoric stress field at $t=0 \mathrm{Myr}$ and after $15 \mathrm{Myr}$. Contour lines are spaced $100 \mathrm{MPa}$. 

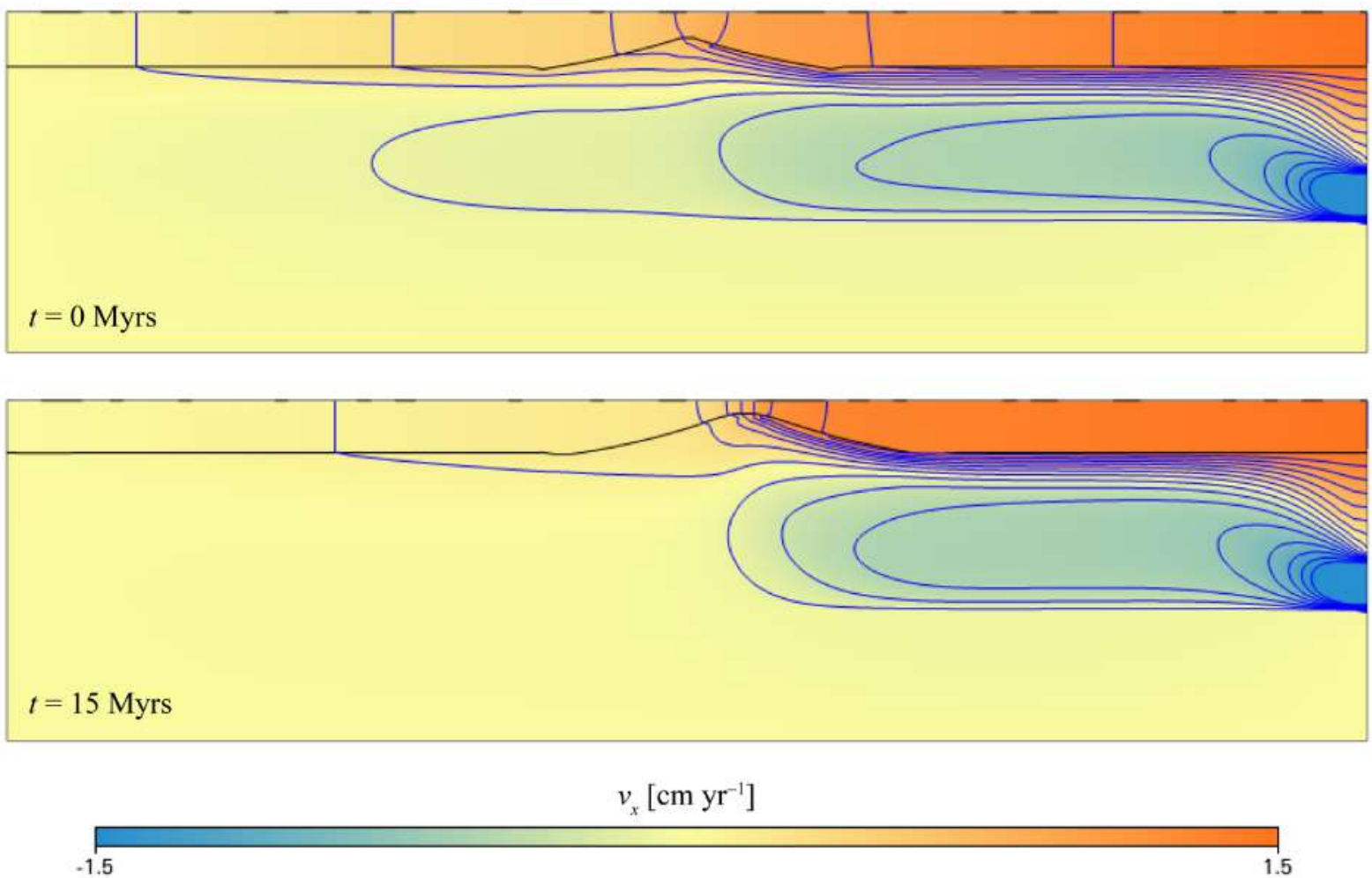

Figure 19. Component $x$ of the velocity field at $t=0 \mathrm{Myr}$ and after $15 \mathrm{Myr}$. Contour lines are spaced $0.2 \mathrm{~cm} \mathrm{yr}^{-1}$.
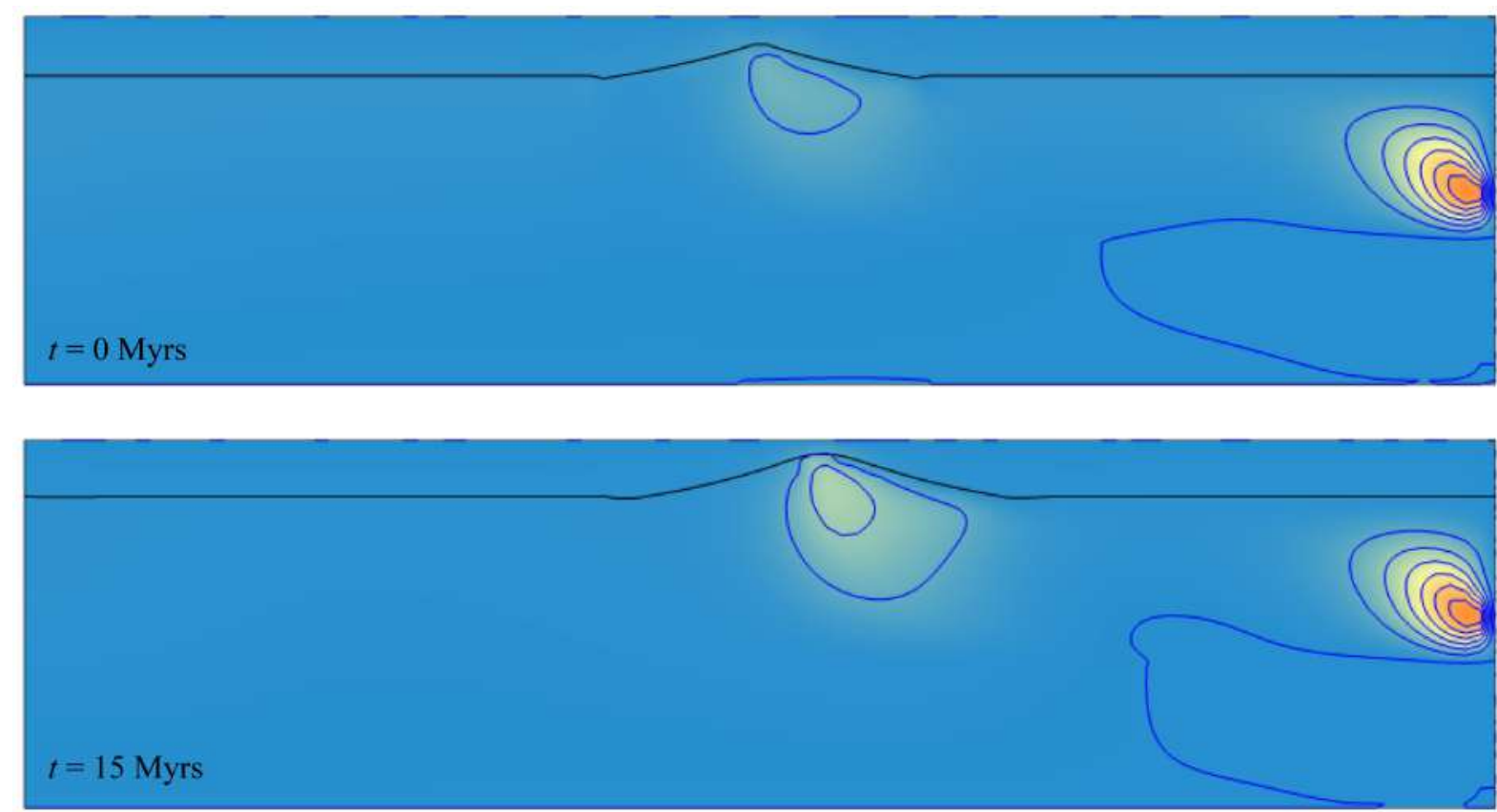

$v_{y}\left[\mathrm{~cm} \mathrm{yr}^{-1}\right]$

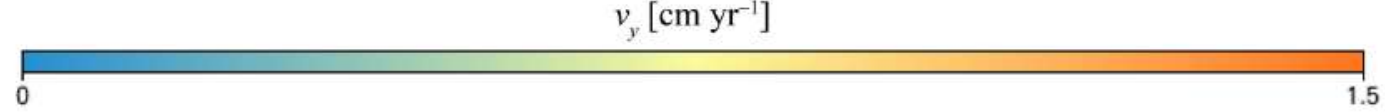

Figure 20. Component $y$ of the velocity field at $t=0 \mathrm{Myr}$ and after $15 \mathrm{Myr}$. Contour lines are spaced $0.2 \mathrm{~cm} \mathrm{yr}^{-1}$. 


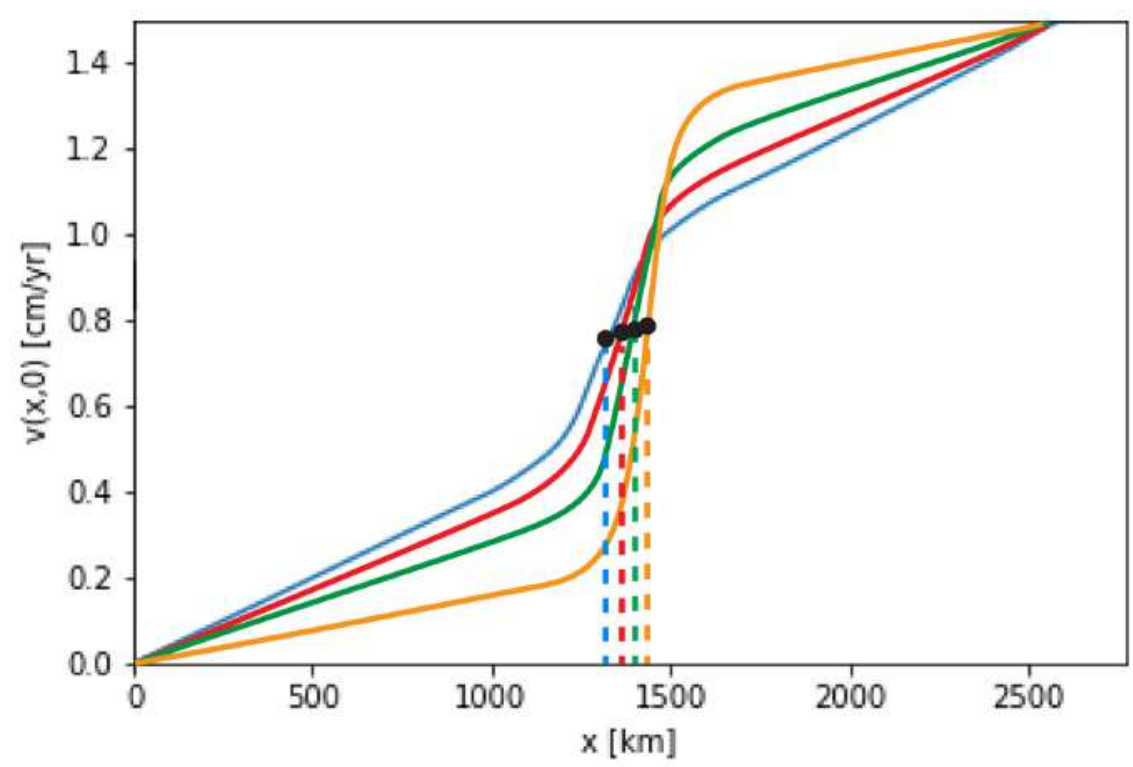

Figure 21. Evolution of the plate velocity field $v(x, 0, t)$ at the Earth's surface. Blue $=0 \mathrm{Myr}$, red $=5 \mathrm{Myr}$, green $=10 \mathrm{Myr}$, orange $=15 \mathrm{Myr}$. The offset of the rift axis at $t=0,5,10,15 \mathrm{Myr}$ is also indicated (dashed lines).

seafloor spreading the predicted velocity field is homogeneous and close to zero in the western area, and nearly equal to $v_{0}$ to the east of the rift axis, consistently with the development of mature passive margins for the two newly formed quasi-rigid tectonic plates. However, the anelastic relaxation model presented above requires that for a short time interval (a few million years) after the onset of seafloor spreading the plate velocity will be negative across the western margin and greater than the far-field velocity $v_{0}$ in the eastern area, consistently with the process of contraction and strain recovery discussed in the previous sections. A second important result of the numerical model is associated with the formation of a proto-melting regime in a low-viscosity zone below the rift axis. An interesting aspect of this feature is its asymmetry (Fig. 20), which should favour the onset of syn-rift volcanism only along the eastern margin, in agreement with the observed distribution of volcanic areas along the Red Sea.

\section{CONCLUSIONS}

We have demonstrated that the initial fast pulse of seafloor spreading in the Red Sea can be theoretically accounted for by non-linear Kelvin-Voigt relaxation of the lithosphere. This initial episode is compatible with the geological and geophysical evidence, which shows that the oldest oceanic crust in the Red Sea formed at high spreading rates and that a short phase of post-rift compression of the conjugate margins occurred after the onset of seafloor spreading.

The best-fitting non-linear lithospheric mantle rheology (modelled with the parameters of olivine) requires a transient viscosity one to two orders of magnitude less than the steady-state viscosity and a corresponding rather hard ('dry') rheology. This results in characteristic times (defined as the time required to reach a longterm 'background' strain rate) of the order of a few million years, in accordance with observations of marine magnetic anomalies. Given the uncertainties in the creep parameters, our numerical conclusions are subject to high margins of uncertainty, but they establish that non-linear anelastic relaxation is in principle a possible mechanism (perhaps in combination with edge-driven convection) for the commonly observed initial fast pulse of seafloor spreading following continental break-up. We have focused only on the transient rheology of the lithospheric mantle. A more complete analysis will have to take into account also the long-term steady-state rheology, which may vary according to composition and temperature, but thatbased on the considerations developed in this paper-is likely to be of non-linear Burgers type, with a non-linear Kelvin component in series with a (also non-linear) viscous component.

Finally, the tectonic structures analysed during our field surveys provide geological evidence of inversion tectonics that is compatible with anelastic relaxation of the lithosphere and corroborates the rheological model presented above. Most likely, the deformation was partitioned along the inherited Neoproterozoic fault as proven by the distribution of seismicity within these tectonic lines. Also, the inherited tectonic lines may have had an influence on the shape and length of the segments of the young Red Sea oceanic ridge.

\section{ACKNOWLEDGEMENTS}

This work was funded by the Italian Ministry of University and Scientific Research, PRIN Schettino, prot. 20125JKANY, and by the Saudi Geological Survey. Giorgio Ranalli acknowledges logistical support from Carleton University. The authors are grateful to the SGS people who helped them in surveying the area and to the SGS drivers who showed great professionality in their difficult work. We would also like to thank the former SGS president Dr Zohair A. Nawab for his kind hospitality in Jeddah. Finally, we thank two anonymous reviewers for their useful suggestions that improved the manuscript.

Author contributions: AS inspired the anelastic relaxation model of rift-drift transition, conducted field work, geophysical data analysis and numerical experiments, and with assistance from GR and DZ wrote the paper. GR with assistance from EF checked the tenability of the rheological model. PPP and DZ contributed to the geology with extensive field work. ET contributed to the interpretation of structural data. NR organized the field missions, coordinated and compiled the results. 


\section{R EFER EN CES}

Abdelfattah, A.K., Al-Amri, A., Abd el-aal, A.K., Zaidi, F.K., Fnais, M., Almadani, S. \& Al-Arifi, N., 2017. The 23 January 2014 Jizan earthquake and its tectonic implications in southwestern Saudi Arabia, Tectonics, 712, 494-502.

Al-Saud, M.M., 2008. Seismic characteristics and kinematic models of Makkah and central Red Sea regions, Arab. J. Geosci., 1(1), 49-61.

Biberger, M. \& Blum, W., 1989. On the natural law of steady state creep, Scr. Metall., 23(8), 1419-1424.

Bonatti, E., 1985. Punctiform initiation of seafloor spreading in the Red Sea during transition from continental to an oceanic rift, Nature, 316, 33-37.

Bosworth, W., Huchon, P. \& McClay, K., 2005. The Red Sea and Gulf of Aden basins. J. Afr. Earth Sci., 43(1), 334-378.

Buck, W.R., 1986. Small-scale convection induced by passive rifting: the cause for uplift of rift shoulders, Earth planet. Sci. Lett., 77, 362-372.

Bürgmann, R. \& Dresen, G., 2008. Rheology of the lower crust and upper mantle: evidence from rock mechanics, geodesy, and field observations, Annu. Rev. Earth Planet. Sci., 36, 531-567.

Courtillot, V., Armijo, R. \& Tapponnier, P., 1987. Kinematics of the Sinai triple junction and a two-phase model of Arabia-Africa rifting, Geol. Soc. London Spec. Publ., 28, 559-573.

Di Giuseppe, E., Faccenna, C., Funiciello, F., van Hunen, J. \& Giardini, D., 2009. On the relation between trench migration, seafloor age, and the strength of the subducting lithosphere, Lithosphere, 1, 121-128.

Dixon, J.E., Dixon, T.H., Bell, D.R. \& Malservisi, R., 2004. Lateral variation in upper mantle viscosity: role of water, Earth planet. Sci. Lett., 222(2), 451-467.

Dixon, T.H., Stern, R.J. \& Hussein, I.M., 1987. Control of Red Sea rift geometry by Precambrian structures, Tectonics, 6, 551-571.

Evans, H.E. \& Knowles, G., 1977. A model of creep in pure materials, Acta Metall., 25(8), 963-975.

Faul, U.H. \& Jackson, I., 2005. The seismological signature of temperature and grain size variations in the upper mantle, Earth planet. Sci. Lett., 234, 119-134.

Faul, U.H. \& Jackson, I., 2015. Transient creep and strain energy dissipation: an experimental perspective, Annu. Rev. Earth Planet. Sci., 43, 541-569.

Fernàndez, M. \& Ranalli, G., 1997. The role of rheology in extensional basin formation modelling, Tectonophysics, 282(1-4), 129-145.

Fierro, E., 2018, Geodynamic modelling of the rift-drift transition: application to the Red Sea. PhD thesis, University of Camerino, pp. 87.

Fnais, M., Al-Amri, A., Abdelrahman, K., Abdelmonem, E. \& El-Hady, S., 2015. Seismicity and seismotectonics of Jeddah-Makkah region, WestCentral Saudi Arabia, J. Earth Sci., 26(5), 746-754.

Freed, A.M., Bürgmann, R., Calais, E. \& Freymueller, J., 2006. Stressdependent power-law flow in the upper mantle following the 2002 Denali, Alaska, earthquake, Earth Planet. Sci. Lett., 252(3), 481-489.

Freed, A.M., Herring, T. \& Bürgmann, R., 2010. Steady state laboratory flow laws alone fail to explain postseismic observations, Earth planet. Sci. Lett., 300, 1-10.

Freed, A.M., Hirth, G. \& Behn, M.D., 2012. Using short-term postseismic displacements to infer the ambient deformation conditions of the upper mantle, J. Geophys. Res., 117, B01409, doi:10.1029/2011JB008562.

Fritz, H. et al., 2013. Orogen styles in the East African Orogen: a review of the Neoproterozoic to Cambrian tectonic evolution, J. Afr. Earth Sci., 86, 65-106.

Funiciello, F., Faccenna, C., Heuret, A., Lallemand, S., Di Giuseppe, E. \& Becker, T.W., 2008. Trench migration, net rotation and slab - mantle coupling, Earth planet. Sci. Lett., 271, 233-240.

Garson, M.S. \& Krs, M., 1976. Geophysical and geological evidence of the relationship of Red Sea transverse tectonics to ancient fractures, Geol. Soc. Am. Bull., 87, 169-181.

Ghebreab, W. \& Talbot, C. J., 2000. Red Sea extension influenced by PanAfrican tectonic grain in eastern Eritrea, J. Struct. Geol., 22, 931-946.

Hamimi, Z., El-Sawy, K., El-Fakharani, A., Matsah, M., Shujoon, A. \& El-Shafei, M. K., 2014. Neoproterozoic structural evolution of the NEtrending Ad-Damm shear zone, Arabian shield, Saudi Arabia, J. Afr. Earth Sci., 99, 51-63.
Hargrove, U.S., Stern, R.J., Kimura, J.I., Manton, W.I. \& Johnson, P.R., 2006. How juvenile is the Arabian-Nubian Shield? Evidence from Nd isotopes and pre-Neoproterozoic inherited zircon in the Bi'r Umq suture zone, Saudi Arabia, Earth planet. Sci. Lett., 252(3), 308-326.

Hirth, G. \& Kohlstedt, D., 2003. Rheology of the upper mantle and the mantle wedge: a view from experimentalists, in Inside the Subduction Factory, Geophysical Monograph Series, Vol. 138, pp. 83-105, ed., Eiler J., American Geophysical Union

Hoechner, A., Sobolev, S.V., Einarsson, I. \& Wang, R., 2011. Investigation on afterslip and steady state and transient rheology based on postseismic deformation and geoid change caused by the Sumatra 2004 earthquake, Geochem. Geophys. Geosyst., 12, Q07010, doi:10.1029/2010GC003450.

Karato, S.-I. \& Wu, P., 1993. Rheology of the upper mantle: a synthesis, Science, 260, 771-778.

King, S.D. \& Anderson, D.L., 1998. Edge-driven convection, Earth planet. Sci. Lett., 160(3), 289-296.

Korostelev, F. et al., 2015. Upper mantle structure of the southern Arabian margin: insights from teleseismic tomography, Geosphere, 11(5), 12621278 .

Korostelev, F. et al., 2016. Magmatism at continental passive margins inferred from ambient-noise phase-velocity in the Gulf of Aden, Terra Nova, 28(1), 19-26.

Koulakov, I., El Khrepy, S., Al-Arifi, N., Sychev, I. \& Kuznetsov, P., 2014. Evidence of magma activation beneath the Lunayyir basaltic field (Saudi Arabia) from attenuation tomography, Solid Earth Discuss., 6, 14011421.

Li, Z.X.A., Lee, C.T.A., Peslier, A.H., Lenardic, A. \& Mackwell, S.J., 2008. Water contents in mantle xenoliths from the Colorado Plateau and vicinity: implications for the mantle rheology and hydration-induced thinning of continental lithosphere, J. geophys. Res., 113, B09210, doi:10.1029/2007JB005540.

Ligi, M. et al., 2011. Initial burst of oceanic crust accretion in the Red Sea due to edge-driven mantle convection, Geology, 391(11), 1019-1022.

Ligi, M. et al., 2012. Birth of an ocean in the Red Sea: initial pangs, Geochem. Geophys. Geosyst. 13(8), Q08009 doi:10.1029/2012GC004155.

Ligi, M., Bonatti, E., Bosworth, W. \& Ronca, S., 2018. Oceanization starts at depth during continental rupturing in the northern Red Sea, in Geological Setting, Palaeoenvironment and Archaeology of the Red Sea, pp.131-157, eds Rasul, N. \& Stewart, I.C.F., Springer-Verlag.

Liu, L. \& Zoback, M.D., 1997. Lithospheric strength and intraplate seismicity in the New Madrid seismic zone, Tectonics, 16(4), 585-595.

Lucazeau, F. et al., 2008. Persistent thermal activity at the Eastern Gulf of Aden after continental break-up, Nat. Geosci., 1(12), 854-858.

Makris, J. \& Rihm, R., 1991. Shear-controlled evolution of the Red Sea: pull apart model, Tectonophysics, 198(2), 441-466.

Moresi, L., Dufour, F. \& Mühlhaus, H.B., 2003. A Lagrangian integration point finite element method for large deformation modeling of viscoelastic geomaterials, J. Comput. Phys., 184(2), 476-497.

Moresi, L., Quenette, S., Lemiale, V., Meriaux, C., Appelbe, B. \& Mühlhaus, H.B., 2007. Computational approaches to studying non-linear dynamics of the crust and mantle, Phys. Earth planet. Inter., 163(1), 69-82.

Müller, G., 1986. Generalized Maxwell bodies and estimates of mantle viscosity, Geophys. J. R. astr. Soc., 87, 1113-1141.

Nielsen, T.K. \& Hopper, J.R., 2004. From rift to drift: mantle melting during continental breakup, Geochem. Geophys. Geosyst., 5(7), Q07003, doi:10.1029/2003GC000662.

Pallister, J.S., 1983. Reconnaissance geologic map of the Harrat Tuffil quadrangle, sheet 20/39 B, Kingdom of Saudi Arabia, Open-File Report USGS-OF-03-33.

Pallister, J.S. et al., 2010. Broad accommodation of rift-related extension recorded by dyke intrusion in Saudi Arabia, Nat. Geosci., 3, 705-712.

Panet, I., Pollitz, F., Mikhailov, V., Diament, M., Banerjee, P. \& Grijalva, K., 2010. Upper mantle rheology from GRACE and GPS postseismic deformation after the 2004 Sumatra-Andaman earthquake, Geochem. Geophys. Geosyst., 11(6), Q06008, doi:10.1029/2009GC002905.

Passchier, C.W. \& Trouw, R.A.J., 2005. Microtectonics, 2nd edn., pp. 366, Springer. 
Peltier, W.R., 1985. New constraints on transient lower mantle rheology and internal mantle buoyancy from glacial rebound data, Nature, 318, 614-617.

Peltier, W.R., Yuen, D.A. \& Wu, P., 1980. Postglacial rebound and transient rheology, Geophys. Res. Lett., 7(10), 733-736.

Pollitz, F.F., 2003. Transient rheology of the uppermost mantle beneath the Mojave Desert, California, Earth planet. Sci. Lett., 215, 89-104.

Pollitz, F.F., 2005. Transient rheology of the upper mantle beneath central Alaska inferred from the crustal velocity field following the 2002 Denali earthquake, J. geophys. Res., 110, B08407, doi:10.1029/2005JB003672.

Qiu, Q., Moore, J.D.P., Barbot, S., Feng, L. \& Hill, M.E., 2018. Transient rheology of the Sumatran mantle wedge revealed by a decade of great earthquakes. Nat. Commun., 9, doi:10.1038/s41467-018-03298-6.

Ranalli, G., 1995. Rheology of the Earth, 2nd edn., pp. 413, Chapman \& Hal.

Ranalli, G. \& Murphy, D.C., 1987. Rheological stratification of the lithosphere, Tectonophysics, 132(4), 281-295.

Salerno, V.M., Capitanio, F.A., Farrington, R.J. \& Riel, N., 2016. The role of long-term rifting history on modes of continental lithosphere extension, J. geophys. Res., 121, 8917-8940.

Sato, H., 1991. Viscosity of the upper mantle from laboratory creep and anelasticity measurements in peridotite at high pressure and temperature, Geophys. J. Int., 105, 587-599.

Schettino, A., 2014. Quantitative Plate Tectonics, pp. 403, Springer.

Schettino, A., Macchiavelli, C., Pierantoni, P.P., Zanoni, D. \& Rasul, N., 2016. Recent kinematics of the tectonic plates surrounding the Red Sea and Gulf of Aden, Geophys. J. Int., 207, 457-480.

Schettino, A.,Macchiavelli \& Rasul, N., 2018. Plate motions around the Red Sea since the Early Oligocene, in Geological Setting, Palaeoenvironment and Archaeology of the Red Sea, pp. 203-220, eds Rasul, N. \& Stewart, I.C.F., Springer-Verlag.

Schlische, R.W., Withjack, M.O. \& Olsen, P.E., 2003. Relative timing of CAMP, rifting, continental breakup, and inversion: tectonic significance, in The Central Atlantic Magmatic Province: Insights from Fragments of Pangea, Geophysical Monograph 136, pp. 33-59, eds Hames, W.E., McHone, G.C., Renne, P.R. \& Ruppel, C.R., American Geophysical Union.

Stocker, R.L. \& Ashby, M.F., 1973. On the empirical constants in the Dorn equation, Scr. Metall., 7(1), 115-120.

Van Wijk, J., Van Hunen, J. \& Goes, S., 2008. Small-scale convection during continental rifting: evidence from the Rio Grande rift, Geology, 36(7), 575-578.

Withjack, M.O., Olsen, P.E. \& Schlische, R.W., 1995. Tectonic evolution of the Fundy rift basin, Canada: evidence of extension and shortening during passive margin development, Tectonics, 14(2), 390-405.

Wright, T.J. et al., 2012. Geophysical constraints on the dynamics of spreading centres from rifting episodes on land, Nat. Geosci., 5(4), 242-250.

Zahran, H.M., Sokolov, V., Roobol, M.J., Stewart, I.C., Youssef, S.E.H. \& El-Hadidy, M., 2016. On the development of a seismic source zonation model for seismic hazard assessment in western Saudi Arabia, J. Seismol., 20(3), 747-769.

\section{SUPPORTING INFORMATION}

Supplementary data are available at $G J I$ online.

Figure S1. Viscosity field at $t=0 \mathrm{Myr}$ and after $15 \mathrm{Myr}$. Contour lines are spaced $1 \log$ Pas.

Figure S2. Second invariant of the strain rate field at $t=0 \mathrm{Myr}$ and after 15 Myr. Contour lines are spaced $1 \log \mathrm{s}^{-1}$.

Supplementary Movies.zip

Please note: Oxford University Press are not responsible for the content or functionality of any supporting materials supplied by the authors. Any queries (other than missing material) should be directed to the corresponding author for the paper. 